\title{
- O campo da democracia digital brasileira: uma análise cientométrica de artigos publicados entre 1999 e 2020
}

\author{
Rafael Cardoso Sampaio ${ }^{1,2}$ \\ Christiana Soares de Freitas $^{3}$ \\ Nilton Cesar Monastier Kleina ${ }^{4}$ \\ Djiovanni Jonas França Marioto 5 \\ Bruno Washington Nichols 6 \\ Tiago Philippini Ferreira Borges da Silva ${ }^{7}$ \\ Murilo Brum Alison ${ }^{8}$ \\ Gabriel Alexandre Bozza 9 \\ Victor Hausen ${ }^{10,11}$ \\ DOI: 10.1590/0103-3352.2022.37.250615
}

\section{Introdução}

A popularização da internet comercial e a maior oferta de computadores pessoais a partir da segunda metade da década de 1990, consolidando-se

Para replicação dos dados: https://doi.org/10.7910/DVN/RBY72G

2 Professor da Universidade Federal do Paraná (UFPR), Programa de Pós-Graduação em Comunicação (PPGCOM) e Programa de Pós-Graduação em Ciência Política (PPGCP), Curitiba, PR, Brasil. E-mail: cardososampaio@gmail.com

3 Professora da Universidade de Brasília (UnB), Programa de Pós-Graduação em Comunicação, Brasília, DF, Brasil. E-mail: freitas.christiana@gmail.com

4 Doutorando da Universidade Federal do Paraná (UFPR), Programa de Pós-Graduação em Comunicação (PPGCOM), Curitiba, PR, Brasil. E-mail: nckleina@gmail.com

5 Doutorando da Universidade Federal do Paraná (UFPR), Programa de Pós-Graduação em Ciência Política (PPGCP), Curitiba, PR, Brasil. E-mail: djiovannimarioto@gmail.com

6 Doutorando da Universidade Federal do Paraná (UFPR), Programa de Pós-Graduação em Ciência Política (PPGCP), Curitiba, PR, Brasil. E-mail: brunonichols@outlook.com

7 Doutorando da Universidade Federal do Paraná (UFPR), Programa de Pós-Graduação em Ciência Política (PPGCP), Curitiba, PR, Brasil. E-mail: tpfbsilva@gmail.com

8 Doutorando da Universidade Federal do Paraná (UFPR), Programa de Pós-Graduação em Ciência Política (PPGCP), Curitiba, PR, Brasil. E-mail: murilo43@hotmail.com

9 Doutorando da Universidade Federal do Paraná (UFPR), Programa de Pós-Graduação em Ciência Política (PPGCP), Curitiba, PR, Brasil. E-mail: gabrielbozz@gmail.com

10 Mestrando da Universidade Federal do Paraná (UFPR), Programa de Pós-Graduação em Informática, Curitiba, PR, Brasil. E-mail: hausen.victor@gmail.com

11 Todos os autores são pesquisadores do Instituto Nacional de Ciência e Tecnologia sobre Democracia Digital (INCT.DD), com sede na Universidade Federal da Bahia, Salvador, BA, Brasil. 
no início dos anos 2000, significou uma retomada acadêmica a temas de estudo que relacionam, de forma ampla, a participação, engajamento cívico e serviços e equipamentos para comunicações digitais online. Essas reflexões indicam uma retomada do estabelecimento de conexões entre regimes democráticos e tecnologias. Por suas características que fomentam a comunicação - inclusive direta, entre cidadãos e elite política - e pela quebra do polo de emissão, as diversas plataformas e ferramentas foram vistas como passíveis do fomento de uma ideia de democracia digital, transcendendo distâncias políticas e constituindo interações entre as mais diferentes esferas (COLEMAN; BLUMLER, 2009). Em certo momento, significou também a digitalização de práticas democráticas sob o questionamento de "o que a internet pode fazer pela democracia?” (VEDEL, 2006; ROTHBERG, 2008; SILVA; BRAGATTO; SAMPAIO, 2016). Posteriormente, a literatura centrou-se nas diversas utilizações de tais tecnologias por indivíduos, agentes da sociedade civil e das instituições políticas formais para o incremento de valores democráticos.

Naturalmente, essa recente relação entre os meios digitais e os diferentes conceitos de democracia teve um acompanhamento próximo do meio acadêmico. Segundo Wilson Gomes (2016), trata-se de mais de duas décadas de produção crescente, que resultou em uma especialização cada vez maior da temática e que dividiu esses estudos sobre internet e política em ao menos três subcampos: política online, democracia digital e estado digital. Entretanto, com essa especialização, hoje se trataria mais de área de convergência de interesses do que um campo acadêmico organizado de fato.

Em termos de Brasil, as principais pesquisas bibliográficas na área voltam-se a estudos sobre temáticas mais amplas, como o que se convencionou chamar de "Internet \& Política". Esses estudos têm evidenciado que a democracia digital é um dos temas centrais, porém seus recortes tendem a estar fechados em Comunicação e nas áreas das Ciências Sociais (ALDÉ; SANTOS J.; SANTOS V., 2018; SAMPAIO; BRAGATTO; NICOLÁS, 2016; SANTOS J.; ALDÉ; SCHWAMBACH, 2016).

Especificamente sobre democracia digital, temos dois conjuntos de trabalhos. Focados na área de Administração, os primeiros evidenciaram que se trata de uma temática com pouca penetração e fortemente ligada a outros temas, como governo digital, e governança digital (PINHO et al., 2019; 
PRZEYBILOVICZ; CUNHA; COELHO, 2015; VIANNA JÚNIOR; ABREU; BATISTA, 2018). Já o segundo envolve estudos com objetos de pesquisa mais restritos. Enquanto Curtinovi e Parmeggiani (2015) se detiveram sobre teses e dissertações, Freitas et al. (2020) analisaram apenas a literatura que estuda o projeto e-Democracia da Câmara dos Deputados.

Portanto, o presente trabalho pretende suprir a lacuna dessas pesquisas apresentando um estudo abrangente sobre a democracia digital na literatura acadêmica brasileira. Propomos um estudo que verifique os periódicos científicos independente de suas áreas de origem e tendo um recorte temporal similar ao de Gomes (2016) - de duas décadas -, especificamente, de 1999 a 2020. Portanto em comparação a estudos anteriores, a pesquisa em tela avança em uma escala de artigos, amplitude temporal e diversidade disciplinar inéditas. Nosso objetivo principal é elencar as diferentes características da literatura nacional sobre a temática. Além disso, buscamos compreender se, em alguma medida, a mesma já se conforma como um campo. Portanto, a nossa pergunta de pesquisa é: podemos falar de um campo da democracia digital no Brasil? Evidente, isso também demanda que tratemos de suas características.

Nesse sentido, o artigo apresenta, para além dessa introdução, duas seções sobre a democracia digital. A primeira desenvolve uma breve apresentação sobre o conceito utilizado aqui e a segunda realiza uma compreensiva revisão dos artigos cientométricos que já analisaram internet e política e também democracia digital. Em seguida, detalhamos a nossa metodologia e a justificativa para algumas escolhas. Analisamos 502 artigos publicados em periódicos brasileiros sobre a temática entre 1999 e 2020 e recuperados através do Google Scholar (GS) e da base indexadora DOAJ pela plataforma Dimensions. Com base em estudos anteriores (SAMPAIO; BRAGATTO; NICOLÁS, 2016), usamos a técnica de pesquisa de análise de conteúdo para evidenciar as principais características da literatura em termos de autores (nome, sexo, instituição, quantidade, escolaridade, área de atuação e parcerias), artigos (ano e periódico), abordagem (vertente social ou institucional), objeto político, objeto tecnológico, abordagem teórica e métodos empregados (empírico ou teórico, método, técnica de pesquisa e uso de estatística). Paralelamente, realizamos uma análise de redes com as principais referências citadas no artigo para compreender como se dão as interações entre as diferentes áreas de conhecimento. 
Em seguida, os resultados são apresentados com as frequências das categorias já denotadas e um cruzamento inicial entre certas categorias, buscando explorar as características dos subcampos presentes através de testes de qui-quadrado e resíduos padronizados. Finalmente, a conclusão oferece reflexões acerca dos comportamentos da pesquisa sobre democracia digital, suas similaridades e diferenças com a pesquisa sobre "Internet \& Política", e outros caminhos de pesquisa a serem seguidos.

\section{O conceito de democracia digital}

A e-democracia é geralmente entendida como qualquer "emprego de tecnologias digitais de comunicação com o objetivo de corrigir, incrementar ou incorporar novos procedimentos ao processo político, no sentido de melhor atender a um ou mais princípios da democracia" (ALMADA et al., 2019, p. 163). Mas, de maneira ampla, pode-se entender democracia digital como uma temática que lida com a complexa relação entre tecnologias digitais de comunicação e as práticas democráticas. Segundo Silva, Bragatto e Sampaio (2016, p. 19), tratam-se de duas dimensões paralelas que se acoplaram - nomeadamente, a "tradição da concepção de democracia e todo o seu debate histórico, normativo e prático enquanto sistema político" com a dimensão das "inovações interativas das tecnologias digitais e toda sua expansão para a vida cotidiana, aplicada para solucionar problemas comunicativos e informativos modernos".

Para Silva, Bragatto e Sampaio (2016), isso significa admitir que o conceito de democracia digital apresenta, em primeiro lugar, um teor normativo intrínseco, uma vez que está vinculado à tradição democrática e suas deontologias. Afinal, a democracia digital é sempre vista como algo que pode melhorar o sistema político-democrático, excluindo da sua avaliação o uso de tecnologias para ações autoritárias, que anulem ou suprimam práticas democráticas. Consequentemente, em segundo lugar, a democracia digital enquanto campo de pesquisa tem uma inspiração empírica baseada em experiências práticas, que devem buscar solucionar problemas reais do sistema político através de aplicações, projetos e iniciativas em seu sentido amplo (SILVA; BRAGATTO; SAMPAIO, 2016).

Ao analisar duas décadas de literatura internacional sobre o tema, Wilson Gomes (2016) sugere que o campo é mais amplo, sendo formado na verdade por três grandes classes: "Democracia Digital", "Política Online", e "Estado 
Digital”. A divisão ocorreria, conforme a visão de Gomes, pelo próprio ponto de partida dos pesquisadores em questão. A grande classe de pesquisadores da democracia digital seria formada, originalmente, por aqueles teóricos da democracia ou da sociedade que perceberam inicialmente o potencial das novas mídias para resolver ou ao menos dirimir os chamados déficits democráticos, aí variando a ênfase democrática a depender dos teóricos em questão (liberal, participacionista, comunitarista, pluralista, deliberacionista etc.). A segunda classe já seria originada por politólogos, interessados em objetos clássicos da política, como Partidos e instituições, Movimentos sociais, Ação política, Eleições e comunicação política (campanhas, noticiário, opinião pública). Finalmente, a terceira classe seria formada por pesquisadores das áreas de Governo, Administração Pública, Processos Legislativos e do Campo de Públicas como um todo, "que encontram nos meios e ambientes digitais uma infinidade de possibilidades e aplicações das questões típicas das suas disciplinas de origem" (GOMES, 2016, p. 50).

Para o autor, este campo de estudos, que chamamos de "Internet \& Política", seria composto pelos três subcampos apresentados. Porém, simultaneamente, não apresentaria as características de fato de um campo acadêmico no sentido mais estrito, podendo ser melhor visto apenas como

uma área de confluência (melhor dizendo, de convivência) de três âmbitos de estudos (de política, de teoria democrática e de Governo e Legislativo) que busca no universo das comunicações digitais aplicações, projetos, experiências e, ousaria dizer, novas perspectivas para objetos tratados tradicionalmente nas suas disciplinas de origem (GOMES, 2016, p. 50-51).

Ainda consoante Gomes (2016), foram necessárias essas duas décadas para existir e se compreender as especificidades de cada subcampo. "E, ainda assim, mantendo-se enormes zonas de intercessão" (p. 51). Ao tratar do subcampo da democracia digital, o autor sugere que há cinco temas principais, sob os quais os estudos se organizariam, a saber: 1) teoria da democracia digital (32\%); 2) e-participação (22\%); 3) e-deliberação ou deliberação online (22\%); 4) e-transparência ou transparência digital (12\%); 5) exclusão digital 
ou digital divide (12\%). Considerando a relevância dos conceitos elencados, passamos agora aos estudos cientométricos ${ }^{12}$ realizados em termos de democracia digital e sobre o campo de "Internet \& Política" (I\&P).

\section{Pesquisa sobre e-democracia no Brasil}

São poucas as tentativas de sistematizar a pesquisa sobre democracia digital no Brasil. Alguns estudos são mais amplos, envolvendo outros conceitos ou mesmo áreas mais vastas, como "Internet e Política" (I\&P), enquanto outros que tratam de democracia digital são focados em certas áreas, com destaque para os estudos e pesquisas em Administração.

O levantamento de Curtinovi e Parmeggiani (2015) mapeou dissertações e teses abordando democracia digital e governo eletrônico da segunda metade da década de 1990 até 2013. Foram encontradas 38 pesquisas empíricas, sendo 27 dissertações de mestrado e 11 teses de doutorado. Os primeiros trabalhos foram apresentados em 2002 (3), sendo 2011 (8) e 2012 (6) os anos com mais defesas. $\mathrm{O}$ trabalho evidencia o destaque da produção em Comunicação (18), seguida por Ciência Política (7) e Administração (7). Em termos de universidades, a Universidade Federal da Bahia (UFBA) (10), a Universidade de Brasília (UnB) (5) e a Universidade Federal do Rio Grande do Sul (UFRGS) (4) são aquelas com mais trabalhos. Além disso, os autores evidenciam que a maior parte da produção sobre democracia digital e governo eletrônico no Brasil trata sobre o poder Executivo (26), com aparição do poder Legislativo em um distante segundo lugar (5).

Por sua vez, com base nas teses e dissertações com a temática "Internet \& Política" do banco de teses e dissertações da Compolítica (COMPOLITICA, 2019), J. Santos, Aldé e Schwambach (2016) verificaram 59 produções no período entre 1992 e 2014. Seus resultados indicam que as cinco universidades com maior produção são: UFBA (13), Universidade Federal Fluminense (UFF) (8), Universidade Federal de Minas Gerais (UFMG) (6), Pontifícia Universidade Católica de São Paulo (PUC-SP) (8) e Universidade Estadual do Rio de Janeiro (UERJ) (7). Ademais, foram identificados 3.632 autores diferentes acionados, porém apenas 24 deles são citados mais de 30 vezes.

12 Resumidamente, tomamos a visão de Grácio (2020, p. 26), segundo a qual, "cientometria compreende, assim, o conjunto de estudos que investigam os diferentes aspectos quantitativos da atividade científica, entre eles, a publicação dos resultados, enquanto disciplina ou atividade econômica [...] Tem por finalidade, avaliar quantitativamente a dinâmica e crescimento da ciência, como atividade social, e os fatores responsáveis pela sua evolução". 
Em seguida, com base no estudo anterior, Aldé, J. Santos e V. Santos (2018) trabalham com as teses e dissertações com a temática "Internet \& Política" do banco de teses e dissertações da Compolítica (COMPOLITICA, 2019), ampliando o período até 2017, alcançando o volumoso número de 119 trabalhos completos. Os autores afirmam a descoberta de 17.714 referências bibliográficas, envolvendo mais de 6.500 pesquisadores distintos, além de dados referentes a 139 bancas de defesa da área envolvendo 65 instituições. A pesquisa evidencia a proeminência de citação dos autores Wilson Gomes, Rousiley Maia, Jamil Marques, André Lemos, Raquel Recuero e Luis Felipe Miguel no território nacional, assim como Manuel Castells, Jürgen Habermas, Pierre Lévy, Pippa Norris, Stephen Coleman e Norberto Bobbio no cenário internacional.

Como já dito, os estudos sobre democracia digital frequentemente convergem com os de governo eletrônico. A avaliação mais completa da área foi realizada por Przeybilovicz, Cunha e Coelho (2015), que buscaram verificar de maneira ampla a produção sobre governo eletrônico na área de Administração no Brasil. Para tanto, os autores prospectaram os principais eventos da área e também a produção de periódicos classificados pela CAPES com conceito igual ou acima de B2 na área de Administração no período entre 2007 e 2012, resultando em 124 artigos de 84 instituições, somando 188 coautorias. O estudo evidencia cinco instituições: a Universidade de São Paulo (USP) (17,7\%), Universidade Federal da Bahia (UFBA) (9,7\%), Pontifícia Universidade Católica do Paraná (PUC-PR) (8,9\%), Fundação Getúlio Vargas (FGV) $(8,1 \%)$ e Universidade de Brasília (UnB) (6,5\%). As autoras também demonstram que a democracia digital é pouco central na literatura de Administração no Brasil, tendo apenas seis trabalhos, especialmente na comparação entre governo eletrônico (33) e e-administração (25).

Na sequência, outros dois estudos recentes investigaram o tema da democracia digital na área de Administração. Vianna Júnior, Abreu e Batista (2018) buscam identificar os artigos relacionados ao tema da democracia participativa digital disponíveis no repositório de eventos da Anpad (Associação Nacional de Pós-Graduação e Pesquisa em Administração) e nas bases de dados SciELO, SPELL e da própria Anpad, no período de 1997 a 2017. Foram encontrados 55 artigos para análise, sendo o primeiro publicado em 1999. Os periódicos com mais artigos foram a Revista de Administração Pública (RAP) 
(10), Organizações \& Sociedade (O\&S) (7) e a Revista Katálysis (4). A pesquisa identificou a existência de 89 autores distintos das seguintes universidades: Universidade Federal de Santa Catarina (UFSC) (9), UFF (9), UFBA (8), Universidade Federal de Viçosa (UFV) (8) e UFMG (7). Uma diferença desse estudo para outros foi o levantamento das principais temáticas abordadas nos artigos, nomeadamente Gestão de Políticas Públicas e Participação (22), Democracia Digital e Governança (13), Governo Eletrônico e Democracia Participativa (10), Políticas Sociais e Participação Popular (6), e Participação Cidadã e Democracia (5).

Estudo semelhante foi realizado por Pinho et al. (2019). O critério do levantamento empírico é o de trabalhos publicados no Brasil de 2002 a 2016 na área "Administração, Ciências Contábeis e Turismo" da Capes em periódicos classificados como A1, A2 ou B, todos com bases disponíveis na plataforma SciELO. Foram encontradas 48 revistas dentro desse recorte. Destes, 21 artigos foram publicados na RAP, sendo que outros cinco periódicos aparecem com destaque, a saber, em O\&S (7), Journal of Information Systems and Technology (6), Revista de Administração da USP (5), Revista de Administração de Empresas (5) e Cadernos Ebape (4). A produção esteve majoritariamente concentrada em FGV (16), UFSC (11), UFBA (9), UnB (8), PUC-PR (6) e USP (6). Os autores denotaram que a maior parte das pesquisas ressaltou abordagens políticas (25) em detrimento das gerenciais (18) e que a temática da democracia digital não aparece consolidada na área de Administração, especialmente quando comparada com governo eletrônico. Entretanto, os autores identificam uma curva de alteração desse quadro a partir de 2011, sugerindo que a área esteja mais atenta a tais iniciativas, havendo espaço para uma produção mais espraiada em termos de instituições e periódicos.

Em perspectiva mais ampla, o estudo de Sampaio, Bragatto e Nicolás (2016) tem a preocupação de entender a formação do campo de "Internet \& Política" como um subcampo da Comunicação e Política no Brasil. O estudo avalia 526 artigos de 11 eventos na área de Comunicação Social, Ciência Política, Sociologia e Ciências Sociais entre 2000 e 2014, sendo que o período entre 2012 e 2014 representa 43,1\% do total de artigos analisados.

No que tange a instituições e autores, o estudo de Sampaio, Bragatto e Nicolás (2016) aponta que há consideravelmente mais autores da Comunicação 
$(45,6 \%)$ do que da Ciência Política (13,9\%), Ciências Sociais $(8,0 \%)$ e Sociologia $(7,4 \%)$. Os dados também evidenciam pouca parceria interinstitucional e principalmente interdisciplinar. Estes autores pertencem em sua maioria à UFBA (9,7\%), PUC-SP $(8,9 \%)$, UFMG $(6,5 \%)$ e a Universidade Federal do Paraná (UFPR) (6,5\%).

No que tange a nossos interesses, os autores identificaram uma série de abordagens teóricas ligadas à democracia digital, como "participação" (20,7\%), "engajamento" (18,3\%) e "deliberação" (9,7\%). Outras questões mais proeminentes da democracia digital, como "transparência" (4,2\%), "inclusão digital" (5,1\%), "identidade e cidadania" (5,3\%) e "accountability" (2,1\%) também foram identificadas.

Em relação aos temas, a pesquisa de Sampaio, Bragatto e Nicolás (2016) evidencia maior interesse pela vertente social $(58,9 \%)$ do que pela institucional (41,1\%), algo confirmado pelos principais objetos políticos dos papers, nomeadamente, "esfera civil não-organizada" (27,6\%), "governo" (24,3\%), "movimentos sociais" (17,9\%) e "campanhas eleitorais" (13,7\%). Percebe-se uma maior parte de estudos de cunho empírico $(66,3 \%)$ e uma robusta quantidade de artigos que utilizaram "análise de conteúdo" (47,7\%) como técnica de pesquisa principal. Finalmente, dos 159 artigos que utilizaram técnicas estatísticas, cabe destacar a preponderância de frequências simples $(65,4 \%)$. Os autores denotam que a "Internet \& Política" apresenta preocupações normativas mais relacionadas aos valores democráticos (deliberação, engajamento, transparência, informação, accountability etc.) do que temas relacionados à pesquisa de comunicação política, como imagem, visibilidade, cobertura jornalística, agendamento ou enquadramento, entre outros. Para eles, isso significa que a "Internet \& Política" no Brasil é fortemente fundamentada e/ou entrecruzada pelos estudos de democracia digital.

Por último, Freitas et al. (2020) montaram uma base de dados elaborada com os 62 estudos sobre o projeto e-Democracia da Câmara dos Deputados (CÂMARA DOS DEPUTADOS, 2009). Diferente dos estudos anteriores, foram avaliadas todas as produções sobre o objeto de 2009 a 2017, incluindo papers, artigos, monografias, dissertações, teses e relatórios. Os anos de 2014 a 2016 apresentam maior produção. Entre as universidades, vemos a entrada do Centro de Formação, Treinamento e Aperfeiçoamento da Câmara dos Deputados (Cefor), 
que teve 13 trabalhos, além da UnB (13), UFSC (7) e UFPR (4). A Ciência Política foi responsável por $26,5 \%$ da produção, enquanto a área de Comunicação representou 12,5\% dos trabalhos, seguidas por Políticas Públicas (11\%) e Direito (9,5\%). Ademais, ao analisar as cocitações, eles destacam Cristiano Faria, Manuel Castells, Joseph Schumpeter, Wilson Gomes, Jamil Marques e Rafael Sampaio como autores mais acionados e cocitados. Ao comparar os resultados aos vistos em Sampaio, Bragatto e Nicolás (2016), os autores concluem que, ao se focar num objeto, notou-se a entrada de novas instituições, como a UnB, e mais destaque de outras áreas, como o Direito e o Campo de Públicas. Entretanto, de forma geral, os dados apontam para mais similitudes com a área de "Internet \& Política", notadamente no que tange os autores mais cocitados.

Ao realizar esta revisão, é possível fazer alguns destaques. Em termos de áreas, os destaques parecem estar claramente na Comunicação seguida da Ciência Política, acompanhada de Sociologia ou Ciências Sociais a depender da classificação. A Administração parece vir num longínquo quarto lugar e o interesse na temática parece ser notadamente mais recente e menor que outros temas, como governo digital. Em termos de instituições, vemos, naturalmente, diferenças causadas pelos interesses e desenhos de pesquisa bastante distintos entre si e pelas pesquisas terem sido focadas, em sua maioria, em certas áreas de pesquisa. Não obstante, UFBA, UFMG e UnB parecem presentes na maioria das pesquisas, indicando serem centros produtores de destaque na temática, enquanto FGV, UFF, UFPR, PUC-PR e UFSC parecem ter mais notoriedade a depender de tema ou área. Nota-se que não há estudos como o agora proposto, que busca investigar os periódicos de maneira transdisciplinar. A maioria restringe-se aos campos da Comunicação e Política ou da Administração e do campo de Públicas e também por isso acaba apresentando um número baixo. Assim, o presente trabalho busca contribuir para a produção de conhecimento na área ao revelar características gerais da literatura sobre democracia digital assim como diferenças existentes entre as áreas de pesquisa atuantes.

\section{Metodologia}

A coleta de dados foi realizada por meio de um script ${ }^{13}$ usando Selenium, uma ferramenta de teste de sistemas web. Ela foi usada para coletar as páginas

13 O script de coleta e transformação dos dados para a produção das redes estão disponibilizadas publicamente no link: https://github.com/Djiovanni/scholar_scraper_democracia_digital. 
dos resultados de busca do Google Scholar (GS) ${ }^{14}$, ou seja, arquivos "html”, que depois foram processados com BeautifulSoup para extrair a URL das páginas das revistas e outros metadados que o GS disponibiliza na página de resultado. Essa busca foi realizada através de múltiplas pesquisas com as principais palavras-chave utilizadas pelo campo. ${ }^{15}$

Dentre as dificuldades encontradas, destacamos a detecção da operação automatizada por parte do GS, além do acionamento de um re-captcha na plataforma. Por esse mecanismo de segurança, a coleta foi paralisada e reiniciada por várias horas em quase todas as tentativas. Notam-se, ainda, a inconsistência dos resultados e a não disponibilização de periódicos além da centésima página, mesmo com a indicação de que havia mais conteúdo disponível.

Outra dificuldade está no grande número de falsos positivos encontrados e nos artigos repetidos verificados pelas diferentes palavras-chave. Um dos problemas do GS é indexar excessivos repositórios, alguns inclusive pouco acadêmicos. Houve, portanto, uma filtragem manual ${ }^{16}$ realizada pelos pesquisadores do grupo, descartando materiais acadêmicos diferentes de artigos publicados em periódicos, como papers de eventos, monografias, dissertações, teses e relatórios, e com base no conceito de democracia digital. Posteriormente, para enriquecer e mesmo validar os dados, foi realizada uma pesquisa pelos mesmos termos na base indexadora Directory of Open Access Journals (DOAJ) através da plataforma Dimensions (DIMENSIONS, 2021), que, em sua versão premium, permite filtrar por país (Brasil). O corpus limpo do GS foi unido ao do DOAJ e os artigos repetidos foram excluídos.

14 A plataforma auxilia na compreensão da transdisciplinaridade do campo. Conforme Mugnaini et al. (2019), 60\% dos periódicos em que pesquisadores brasileiros publicam não estão indexados via SciELO, Scopus ou WoS, representando $41 \%$ dos artigos pulicados.

15 As palavras-chave iniciais foram: "edemocracia", "democracia digital", "democracia eletrônica", "democracia virtual", "democracia online", "democracia AND novas mídias", "democracia AND tecnologia", "ciberdemocracia", "teledemocracia", "democracia AND Internet", "eparticipação", "participação AND tecnologia", "participação AND Internet", "participação AND digital", "participação AND virtual", "participação AND TICs", "participação AND novas mídias", "participação AND online", "participação política online", "participação política digital”, "participação política virtual" "edeliberação", "Deliberação AND Internet", "Deliberação AND digital”, "Deliberação virtual", "Deliberação online", "Esfera Pública \& Internet", "Esfera Pública AND digital”, "Esfera Pública virtual”, "Esfera Pública online”, "etransparência", "transparência digital", "transparência AND novas mídias", "transparência online”, "transparência AND internet", "Transparência AND tecnologia", "Transparência AND TICs", "transparência AND websites" e "Transparência AND portais". Este processo foi revisado com o acréscimo de outras palavras-chave detectadas nos artigos iniciais. Foram acrescentadas: "governo aberto", "dados abertos governamentais", "parlamento aberto", "parlamento digital", "webcidadania", "exclusão digital, "governança eletrônica", "governança digital", "governança da internet", "governança algorítmica", "regulação algorítmica" e "tecnopolítica".

16 Apesar de não ter havido um teste de confiabilidade entre codificadores, ideal para decisões como essa, houve dupla checagem entre codificadores independentes. Em casos de discordância, um terceiro codificador agiu como árbitro para decidir pela inclusão ou não do artigo. 
Em seguida, os artigos foram analisados manualmente com base em análise de conteúdo (NEUENDORF, 2002), tendo o livro de códigos de pesquisa anterior como base (SAMPAIO; BRAGATTO; NICOLÁS, 2016) a partir de pequenas adaptações (SAMPAIO et al., 2021). Basicamente, o objetivo consiste em identificar as principais características dos autores (nome, sexo, instituição, quantidade de participantes, escolaridade, área de atuação e eventuais parcerias), dos artigos (ano e periódico), da abordagem (vertente social ou institucional), objeto político, objeto tecnológico, abordagem teórica e questões sobre os métodos empregados (empírico ou teórico, método, técnica de pesquisa e uso de estatística). Posteriormente, análises cientométricas com base nos resumos, palavras-chave e referências podem ser realizadas.

\section{Resultados}

Ao todo, o processo foi capaz de raspar a referência a 2.847 trabalhos acadêmicos. Após a retirada manual de artigos repetidos, falsos positivos e de trabalhos que não fossem de periódicos (capítulos de livros ${ }^{17}$, papers de eventos, dissertações, teses etc.), identificamos 502 artigos como referentes a estudos ou reflexões sobre democracia digital.

Os dados iniciais apresentados no gráfico 1, a seguir, demonstram que os artigos sobre democracia digital ganham muita força a partir de 2008, quando há algumas ciclagens naturais da literatura, sempre com uma tendência de elevação.

17 Note-se que alguns dos principais autores da área, como Wilson Gomes, priorizaram a produção de capítulos de livro, o que tem certo impacto nos resultados. 
Gráfico 1. Artigos publicados por ano

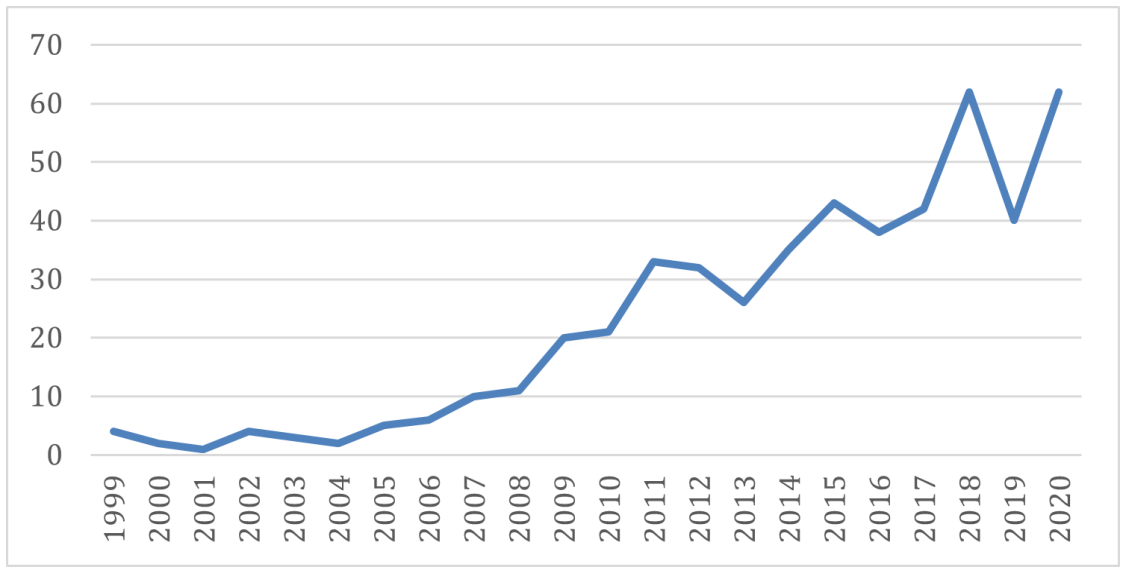

Fonte: Elaboração dos autores

Com isso em mente, os dados iniciais, por ora baseados exclusivamente no primeiro autor de cada artigo, revelam que as universidades com maior produção são UFPR (43 - 8,5\%), UFBA (42 - 8,3\%), UFMG (38 - 7,5\%), UnB (29 - 5,9\%), USP (17 - 3,4\%) e UFSC (16 - 3,2\%), confirmando dados de pesquisas anteriores (CURTINOVI; PARMEGGIANI, 2015; PINHO et al., 2019; PRZEYBILOVICZ; CUNHA; COELHO, 2015; SAMPAIO; BRAGATTO; NICOLÁS, 2016; SANTOS et al., 2016; VIANNA JÚNIOR; ABREU; BATISTA, 2018). Ainda há o aparecimento da Universidade Estadual Paulista, a Unesp (25), e da Universidade Federal de Santa Maria (UFSM) (13) em relação às pesquisas anteriores. As instituições UFF, UFV, UERJ, PUC-PR, PUC-SP, FGV, apontadas como centrais em alguns desses estudos, não obtiveram destaque aqui. Há um total de 138 instituições com ao menos um trabalho publicado em periódico científico sobre as temáticas pesquisadas.

Conforme evidenciado em trabalhos anteriores, a Comunicação segue como a área que apresenta uma considerável maior presença (156) na pesquisa sobre democracia digital (gráfico 2), porém o Direito (81) passa a ocupar a segunda posição no lugar da Ciência Política, que aparece logo em seguida (61). Administração (41) e o Campo de Públicas (32) vêm logo posteriormente, fechando o top 5 das áreas. Destes, destacamos o ingresso do Direito com uma quantidade significativa de trabalhos, área praticamente não detectada em estudos anteriores (exceto em FREITAS et al., 2020). 


\section{Gráfico 2. Área do primeiro autor}

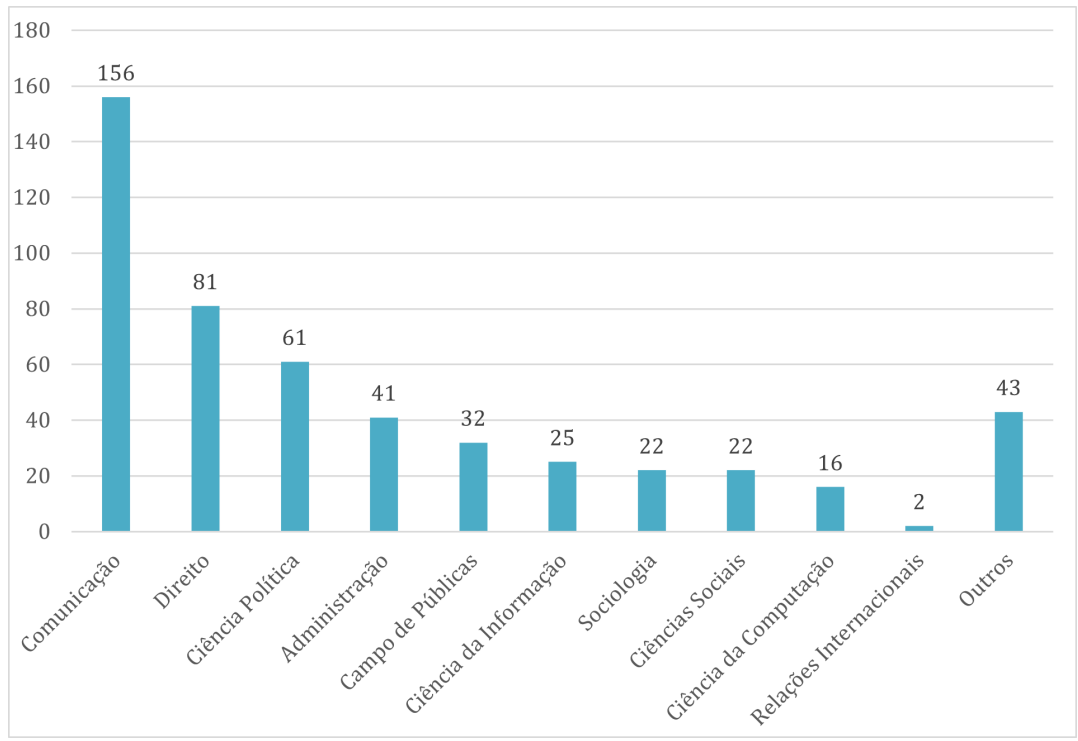

Fonte: Elaboração dos autores

\section{Gráfico 3. Áreas dos autores ao longo dos anos}

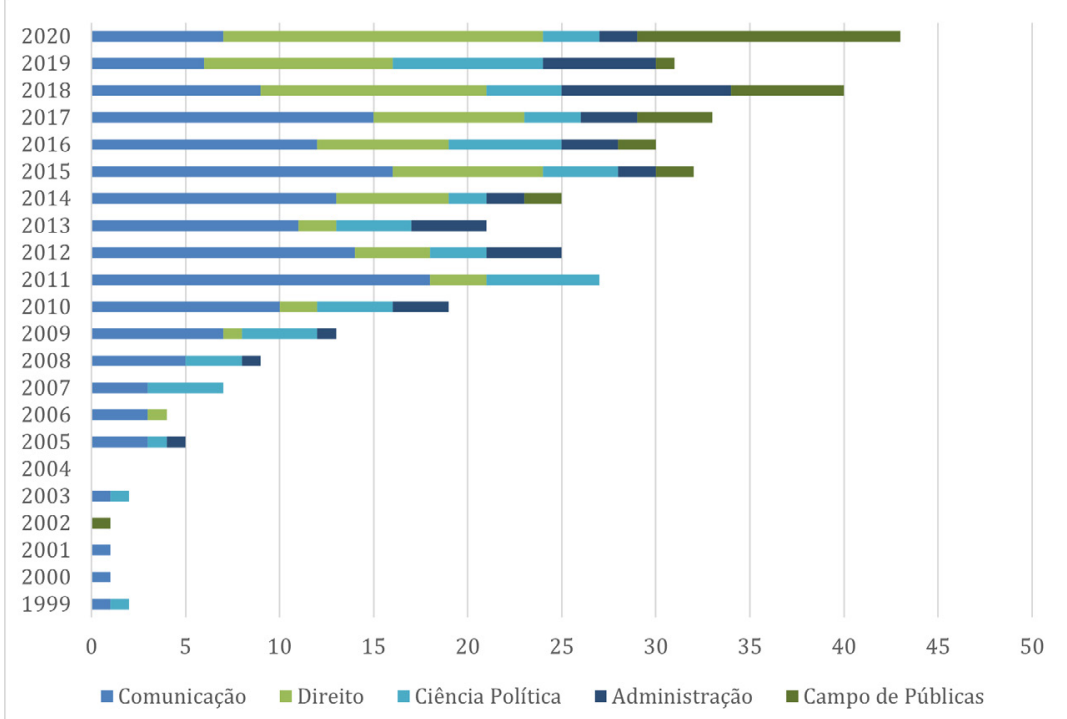


No gráfico longitudinal (gráfico 3), vemos uma retração da produção em Comunicação nos últimos três anos, enquanto, desde 2015, Direito, Administração e o Campo de Públicas apenas aumentam o seu protagonismo na produção da temática. Dos 502 primeiros autores, 286 (57\%) são do sexo masculino e 216 (43\%) do feminino. Finalmente, como já denotado em estudos anteriores, a maioria dos artigos não apresenta nem uma parceria interinstitucional $(75,3 \%)$ e nem interdisciplinar $(74,4 \%)$, evidenciando uma baixa colaboração entre pesquisadores de diferentes áreas e universidades. Não obstante, os gráficos longitudinais apontam um claro aumento ao longo dos anos de ambas as parcerias, notadamente a interdisciplinar (gráfico 4 ).

Gráfico 4. Pesquisa interdisciplinar e parceria interinstitucional ao longo dos anos

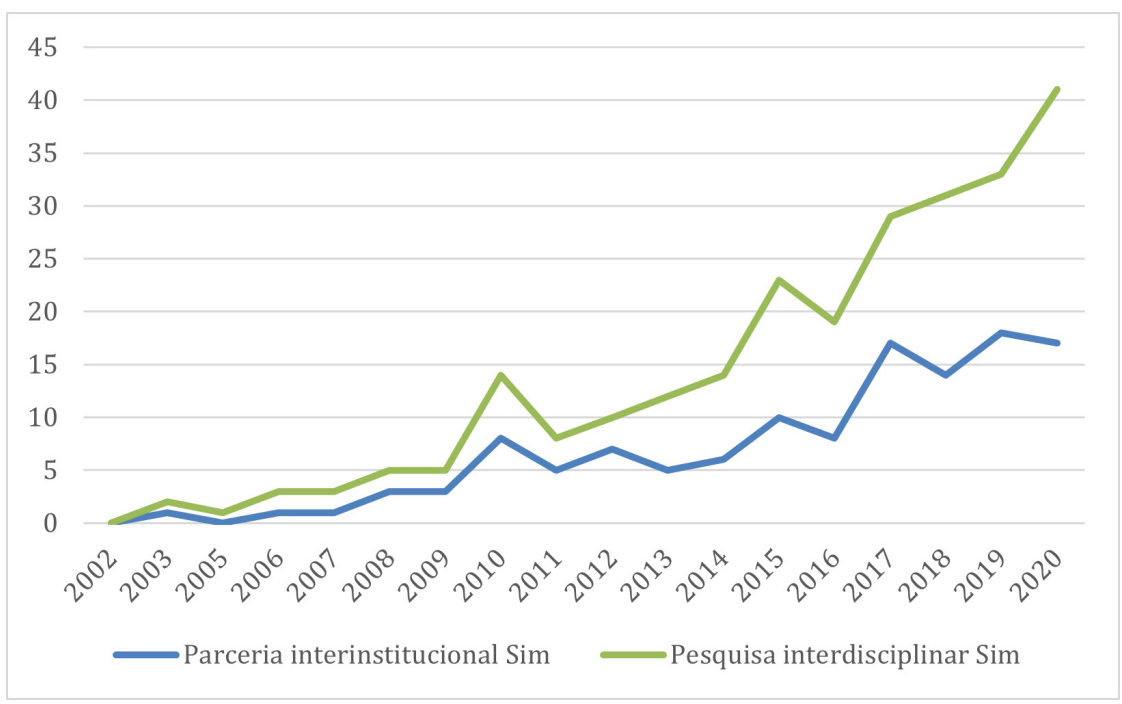

Fonte: Elaboração dos autores

Também foram verificados os periódicos de publicação dos artigos e as referências dos artigos, ambos presentes na tabela 1 . Ao todo foram identificados 261 periódicos, sendo que 92 destes publicaram ao menos dois artigos. A área de Comunicação apresenta o segundo periódico com mais publicações, 
a Revista Compolítica ( $\mathrm{N}=12$ ), além da Liinc em Revista (9) em quinto lugar. Depois, surgem várias revistas com poucas publicações, nomeadamente Intexto (7), Comunicação \& Sociedade, Contemporânea (UFBA), Eptic, Revista Famecos, Revista Fronteiras, Revista Observatório, e Revista Temática, cada uma destas com cinco publicações. Administração e a Administração Pública também apresentam notável destaque com RAP (13), revista com maior produção na temática, O\&S (7), Revista do Serviço Público da ENAP (6), Cadernos EBAPE.BR e Cadernos Gestão Pública e Cidadania, com 4 artigos cada, apresentando dados similares aos vistos em Vianna Júnior, Abreu e Batista (2018) e Pinho et al. (2019). Em terceiro lugar, a Ciência Política também tem destaque nos periódicos com a Revista de Sociologia e Política (11), Opinião Pública (9), Revista Debates (7), Revista Brasileira de Ciência Política (5) e Revista Eletrônica de Ciência Política (5). Apesar do destaque recente do Direito, apenas uma revista aparece com muitas publicações. Trata-se exatamente da única revista dedicada à temática no Brasil, a Revista Democracia Digital e Governo Eletrônico (12).

Tabela 1. Autores mais citados nas referências dos artigos ${ }^{18}$ e periódicos com mais publicações de artigos

\begin{tabular}{cccccccc}
\hline$\#$ & Autor & N & Área de Atuação & $\#$ & Revista & N & Área mãe \\
\hline 1 & GOMES, Wilson & 320 & Comunicação & 1 & $\begin{array}{c}\text { Revista de } \\
\text { Administração } \\
\text { Pública }\end{array}$ & 13 & $\begin{array}{c}\text { Administração } \\
\text { Pública }\end{array}$ \\
\hline 2 & MAIA, Rousiley & 284 & Comunicação & 2 & $\begin{array}{c}\text { Revista Democracia } \\
\text { Digital e Governo } \\
\text { Eletrônico }\end{array}$ & 12 & Direito \\
\hline 3 & HABERMAS, Jürgen & 273 & Filosofia Política & 3 & Revista Compolítica & 12 & Comunicação \\
\hline 4 & MARQUES, Jamil & 256 & Ciência Política & 4 & $\begin{array}{c}\text { Revista de } \\
\text { Sociologia e Política }\end{array}$ & 11 & Ciência Politica \\
\hline 5 & CASTELLS, Manuel & 213 & Sociologia & 5 & Opinião Pública & 9 & Ciência Política \\
\hline 7 & SAMPAIO, Rafael & 206 & Ciência Política & 6 & Liinc em Revista & 9 & Comunicação \\
\hline 8 & PINHO, José & 122 & Administração & 7 & Contemporânea & 7 & Administração \\
\hline 9 & LELVY, Pierre & 121 & Comunicação & 8 & Revista Debates & 7 & Ciência Política \\
\hline 10 & NORRIS, Pippa & 90 & Ciência Política & 10 & $\begin{array}{c}\text { Comunicação \& } \\
\text { Sociedade }\end{array}$ & 6 & Comunicação \\
\hline
\end{tabular}

18 Foram consideradas as áreas de atuação dos autores em 2020 ou a última atuação presente em seus currículos (lattes para brasileiros e páginas pessoais para estrangeiros). 


\begin{tabular}{|c|c|c|c|c|c|c|c|}
\hline$\#$ & Autor & $\mathbf{N}$ & Área de Atuação & $\#$ & Revista & $\mathbf{N}$ & Área mãe \\
\hline 11 & MENDONCA, Ricardo & 86 & Ciência Política & 11 & Em Questão & 6 & Comunicação \\
\hline 12 & AVRITZER, Leonardo & 83 & Ciência Política & 12 & $\begin{array}{l}\text { Organizações \& } \\
\text { Sociedade }\end{array}$ & 6 & $\begin{array}{l}\text { Ciência da } \\
\text { Informação }\end{array}$ \\
\hline 13 & EISENBERG, José & 75 & Ciência Política & 13 & $\begin{array}{c}\text { Revista do Serviço } \\
\text { Público }\end{array}$ & 6 & $\begin{array}{c}\text { Administração } \\
\text { Pública }\end{array}$ \\
\hline 14 & BRAGA, Sérgio & 74 & Ciência Política & 14 & E-Legis & 6 & Ciência Política \\
\hline 15 & BOBBIO, Norberto & 65 & Filosofia Política & 15 & Eptic & 5 & Comunicação \\
\hline 16 & CEPIK, Marco & 63 & Ciência Política & 16 & $\begin{array}{l}\text { Revista Brasileira de } \\
\text { Ciência Política }\end{array}$ & 5 & Ciência Política \\
\hline 17 & MARQUES, Angela & 55 & Comunicação & 17 & $\begin{array}{l}\text { Revista Eletrônica de } \\
\text { Ciência Política }\end{array}$ & 5 & Ciência Política \\
\hline 18 & RECUERO, Raquel & 55 & Comunicação & 18 & Revista Famecos & 5 & Comunicação \\
\hline 19 & DAHLBERG, Lincoln & 54 & Comunicação & 19 & Revista Fronteiras & 5 & Comunicação \\
\hline 20 & FUNG, Archon & 54 & Ciência Política & 20 & Revista Observatório & 5 & Comunicação \\
\hline 21 & AGGIO, Camilo & 51 & Comunicação & 21 & $\begin{array}{l}\text { Revista Tecnologia e } \\
\text { Sociedade }\end{array}$ & 5 & Interdisciplinar \\
\hline 22 & LEMOS, André & 51 & Comunicação & 22 & Temática & 5 & Comunicação \\
\hline 23 & CHADWICK, Andrew & 51 & Comunicação & 23 & $\begin{array}{c}\text { Informação \& } \\
\text { Sociedade: Estudos }\end{array}$ & 5 & $\begin{array}{l}\text { Ciência da } \\
\text { Informação }\end{array}$ \\
\hline 24 & KIES, Raphael & 50 & Ciência Política & 24 & Transinformação & 5 & $\begin{array}{l}\text { Ciência da } \\
\text { Informação }\end{array}$ \\
\hline 25 & BOHMAN, James & 47 & Filosofia Política & 25 & $\begin{array}{l}\text { Cadernos Gestão } \\
\text { Pública e Cidadania }\end{array}$ & 4 & $\begin{array}{l}\text { Administração } \\
\text { Pública }\end{array}$ \\
\hline 26 & DRYZEK, John & 46 & Ciência Política & 26 & $\begin{array}{c}\text { Cadernos PPG-AU/ } \\
\text { UFBA }\end{array}$ & 4 & Arquitetura \\
\hline 27 & PAPACHARISSI, Zizi & 45 & Comunicação & 27 & $\begin{array}{l}\text { Revista de } \\
\text { Informação } \\
\text { Legislativa }\end{array}$ & 4 & Interdisciplinar \\
\hline 28 & SILVA, Sivaldo & 43 & Comunicação & 28 & Revista USP & 4 & Interdisciplinar \\
\hline 29 & MANIN, Bernard & 43 & Filosofia Política & 29 & Cadernos EBAPE.BR & 4 & $\begin{array}{c}\text { Administração } \\
\text { Pública }\end{array}$ \\
\hline 30 & SANTOS, Boaventura & 42 & Sociologia & & & & \\
\hline 31 & MIGUEL, Luis & 40 & Ciência Política & & & & \\
\hline
\end{tabular}

Fonte: Elaboração dos autores

Ainda na tabela 1, estão todos os autores citados com 40 referências ou mais. É possível verificar que os autores mais visitados são semelhantes àqueles encontrados em Comunicação e Política, no geral, e em "Internet e Política”, em específico, (Ver: FREITAS et al., 2020; SANTOS J.; ALDÉ; SCHWAMBACH, 2016; ALDÉ; SANTOS J.; SANTOS V., 2018), fugindo dos padrões vistos em 
pesquisas específicas da Administração, que apresenta apenas um autor entre os mais citados. Essa lista expandida das principais referências nos ajuda a ver algumas questões. Em primeiro lugar, é notável que os principais autores acionados ou atuam na Comunicação (12) ou na Ciência Política (12), sendo que teóricos de Filosofia Política (4) e Sociologia (2) são acionados logo em seguida, evidenciando a ideia de um campo da democracia digital organizado em torno da Comunicação \& Política. Em especial, esse resultado é bem expressivo, uma vez que a principal área da Democracia Digital é a Comunicação. Em outras palavras, mesmo sendo a Comunicação a principal área da Democracia Digital, no somatório, os principais autores acabam sendo aqueles relacionados às práticas políticas (digitais ou não). Em segundo lugar, diferentemente de outras áreas, há um equilíbrio entre autores brasileiros (16) e estrangeiros (15). Também importante notar que há diversos autores que sequer trabalham com o digital, mas que tratam de temáticas caras aos pesquisadores da Democracia Digital. Exemplos incluem democracia participativa e instituições participativas, democracia deliberativa e formas de deliberação pública, democracia liberal e seus críticos, democracia de forma ampla e temas correlatos, como cultura política, inovações democráticas e representação. Há também autores que trabalham com o digital sob outras perspectivas, notadamente a cibercultura, como André Lemos, Pierry Lévy e Raquel Recuero.

Ao realizar uma análise de redes ${ }^{19}$ inicial com as referências (incluindo apenas os autores com 30 ou mais citações), foram encontrados quatro clusters principais, exibidos na figura 1 .

19 Esse processo de clusterização nos permite melhor apreender a estrutura de grafos grandes. E permitiu que definíssemos de forma otimizada o número de clusters e a composição de cada um apresentado neste grafo. A separação do grafo por classe de modularidade produziu 6 clusters (Modularity $=0,443$, Resolution $=1$ ), que foram reduzidos para 4 após a filtragem por número mínimo de citações. O algoritmo de modularidade está descrito em Blondel et al. (2008). 
Figura 1. Grafo das redes de citação

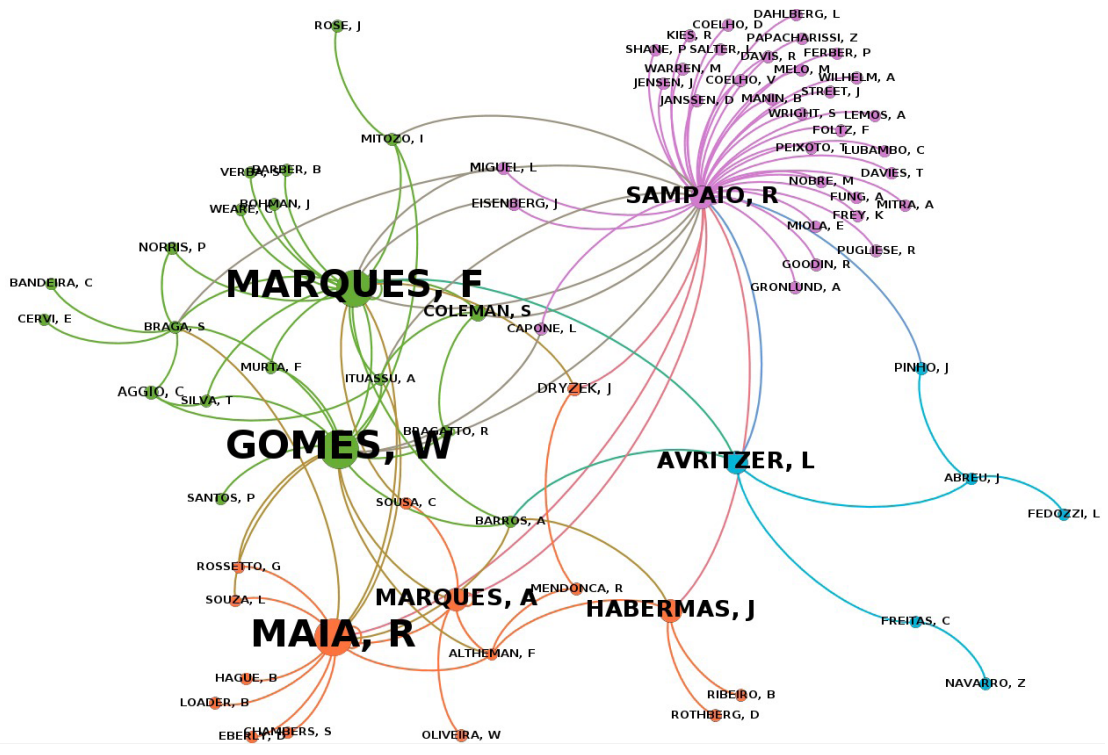

Fonte: Elaboração dos autores

O grafo da figura 1 indica que teríamos dois autores centrais no campo da democracia digital brasileira ${ }^{20}$, a saber Wilson Gomes e Francisco Jamil Marques, conectando algumas das principais referências. ${ }^{21}$ Este grupo também denota pesquisadores oriundos da UFPR, como Sergio Braga, Emerson Cervi, Isabele Mitozo e Rachel Bragatto. Há um grupo deliberacionista, no qual Rousiley Maia, Angela Marques e o próprio Habermas são as figuras essenciais. Conectado a ele, existe um grupo participacionista, no qual Leonardo Avritzer é a referência fundamental ${ }^{22}$, mas que ainda apresenta Antônio Pinho e Julio Abreu, da Administração, e Christiana Freitas, do Campo de Públicas. Por sua vez, há um último grupo com a figura de Rafael Sampaio, que é simultaneamente conectado aos outros grupos, mas também parece distribuir as referências para fora da rede (algo também realizado em alguma medida por Jamil Marques e Rousiley Maia).

20 Fica notável como os quatro clusters são organizados em torno de referências nacionais.

21 Também aqui conseguimos verificar outros pesquisadores da comunicação e política.

22 Apesar de ser um pesquisador com pouca entrada em democracia digital, isso provavelmente se deve pelo grande número de artigos que trata sobre participação política e engajamento, além de inúmeros artigos sobre o orçamento participativo digital em específico. Alguns autores conectados a Avritzer, como Fedozzi e Navarro, denotam isso. 
Como sabemos, Wilson Gomes (UFBA) e Rousiley Maia (UFMG) são alguns dos autores fundadores dos estudos da democracia digital na Comunicação, enquanto Jamil Marques, Rafael Sampaio, Angela Marques, entre outros ${ }^{23}$, foram seus orientandos de doutorado, atuando tanto na Comunicação quanto na Ciência Política, o que parece nos fornecer uma visão da organização das citações. Esses dados são indicativos de outras formas de transdisciplinaridade, ou seja, se, por um lado, os autores ainda não realizam cooperações e parcerias diretas, por outro, as citações parecem ser transdisciplinares, notadamente no que tange às principais referências. Esses dados dialogam diretamente com os analisados em FREITAS et al. (2020), que mostram basicamente os mesmos autores como centrais nos estudos sobre a iniciativa e-Democracia.

A respeito das abordagens, há um claro predomínio da vertente institucional $^{24}\left(271\right.$ - 54\%) sobre a social ${ }^{25}(231$ - 46\%), algo esperado por nossa própria definição de democracia digital e pelas palavras-chave escolhidas. Esses resultados ficam mais nítidos quando verificamos o gráfico 5, que trata dos principais objetos políticos estudados pela democracia digital brasileira.

23 Também podemos ressaltar Ricardo Fabrino Mendonça, Camilo Aggio, e Graça Rossetto.

24 Haveria três eixos: uso institucional diário (três poderes e partidos); iniciativas institucionais (prestação de serviços, estado digital) e iniciativas de pressão e/ou influência (votos, sondagens, tomadas de decisão, deliberações em fóruns).

25 A vertente social se preocupa com as questões societais, então estariam as implicações do meio digital no engajamento cívico (incluindo manifestações e passeatas), na esfera pública, na deliberação política e no capital social. 
Gráfico 5. Objeto político/social predominante dos artigos

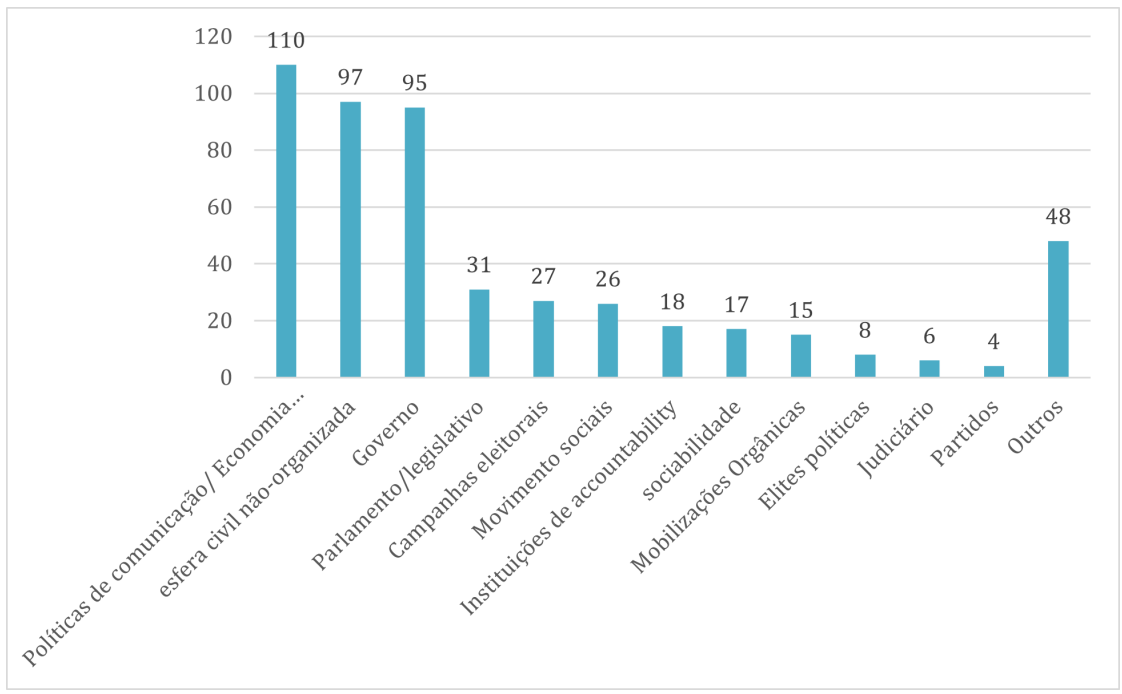

Fonte: Elaboração dos autores

Diferentemente de trabalhos anteriores sobre "Internet \& Política" (SAMPAIO; BRAGATTO; NICOLÁS, 2016), o objeto de "Políticas de Comunicação/Economia Política" se mostra como o mais visitado na literatura de democracia digital. Esse resultado claramente deve-se à forte entrada recente das áreas de Administração, Campo de Públicas e, especialmente, Direito. Depois, segue-se aquilo já visto anteriormente, com a "esfera civil não-organizada/Mobilizações orgânicas" (97) em segundo lugar e "governo" (95) em terceiro. Dois objetos institucionais, Parlamento/legislativo (31) e campanhas eleitorais (27), fecham o top 5 dos objetos mais estudados.

Por sua vez, os dados aqui também vão ao encontro daqueles vistos em Sampaio, Bragatto e Nicolás (2016) no que tange ao objeto tecnológico principal do artigo. O principal objeto é uma reflexão mais ampla sobre a internet, o que é constante ao longo dos anos (vemos um crescimento, em 2020, fruto de reflexões mais amplas advindas do Direito). Em seguida, puxados pelos artigos de transparência e participação, temos os websites. Mídias sociais a essa altura já representam o terceiro objeto mais visitado pela democracia digital (conforme apresentado no gráfico 6), estando em alta. O aparecimento da agenda de dados abertos em 2010 também fica claro no gráfico seguinte, longitudinal (gráfico 7), tornando-se um objeto constante a partir de 2014. 
Gráfico 6. Objeto tecnológico estudado

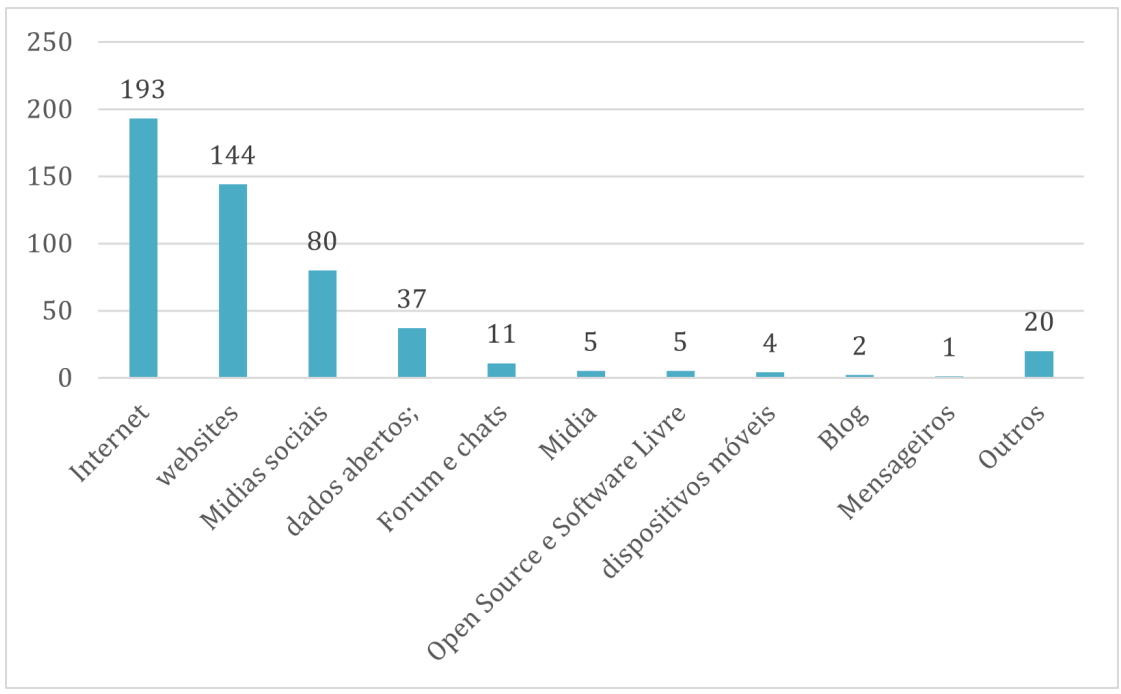

Fonte: Elaboração dos autores

\section{Gráfico 7. Objeto tecnológico abordado ao longo dos anos}

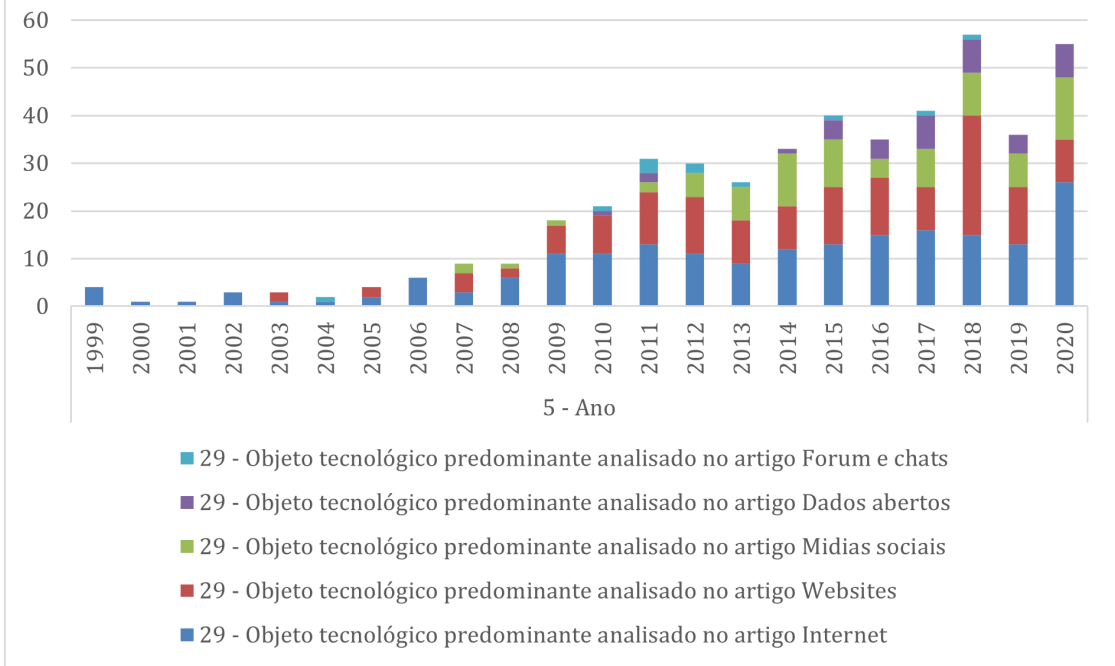

Fonte: Elaboração dos autores 
Avançando em relação aos dados de estudos anteriores, buscamos verificar quais mídias sociais foram as mais estudadas. Comprovou-se o esperado: Facebook é notadamente a rede social mais analisada, sendo objeto de estudo de mais da metade das pesquisas identificadas (41), seguido de Twitter (12), YouTube (11) e Instagram (3).

Seguindo tanto o padrão das pesquisas brasileiras sobre internet e política e sobre democracia digital e governo eletrônico (FREITAS et al., 2020; PINHO et al., 2020; PRZEYBILOVICZ; CUNHA; COELHO, 2015; SAMPAIO; BRAGATTO; NICOLÁS, 2016; VIANNA JÚNIOR; ABREU; BATISTA, 2018) quanto o padrão internacional da pesquisa sobre democracia digital (GOMES, 2016), as três principais abordagens teóricas vistas são sobre transparência e informação (113), participação (97), e deliberação/conversação política (65). Porém, é surpreendente o resultado da transparência em primeiro lugar, algo que não foi apontado em nenhum estudo anterior nacional ou internacional. No caso brasileiro, isso se justifica pelo crescimento evidente de áreas como Administração, Campo de Públicas e Direito, nas quais essas temáticas são mais salientes. Para este estudo (gráfico 8), acrescentamos a opção da abordagem teórica sobre a própria democracia digital, que esteve presente em 53 artigos. Nota-se, ainda, que a teoria da Economia Política e das Políticas de Comunicação é pouco acionada ou, quando presente, não é predominante nos estudos - mesmo sendo este o objeto político mais presente nos artigos analisados. 
Gráfico 8. Abordagem teórica dos artigos

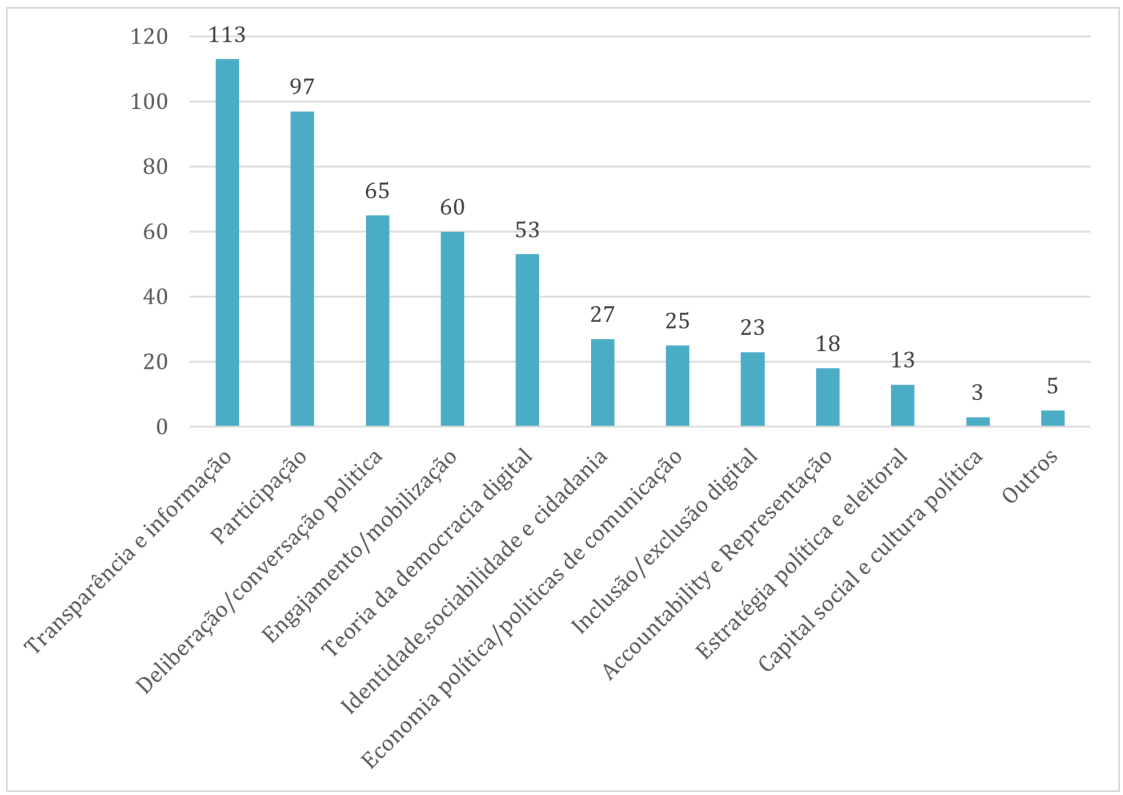

Fonte: Elaboração dos autores

Concluímos, ainda, que a maior parte dos artigos (310) apresentou estudos empíricos (61,8\%), enquanto 192 artigos (38,2\%) foram teóricos. A partir de 2010, passa-se a ter mais artigos empíricos do que teóricos. Dentre os empíricos, a maioria fez uso de métodos bibliográficos (203 - 40,4\%), depois métodos qualitativos (153 - 30,5\%), seguidos por quantitativos (99 - 19,7\%), enquanto 9,4\% (47) fizeram uso de métodos mistos (quanti/quali).

Seguindo os passos de Sampaio, Bragatto e Nicolás (2016), buscava-se compreender quais as técnicas de pesquisa mais acionadas pelos pesquisadores. Como naquele momento havia uma grande predominância do uso da análise de conteúdo (AC), verificou-se a possibilidade de separar essa técnica de análises mais qualitativas. O resultado, para tanto, foi a inclusão do código "análise holística". Ainda assim, a AC foi a mais acionada, estando presente em $58,3 \%(\mathrm{~N}=194)$ dos trabalhos pesquisados, enquanto a análise holística esteve em 19,2\% (64), seguida por análise documental (9,3\% - 31), surveys $(3,9 \%-13)$ e análise do discurso $(3,9 \%-13)$. 
Da mesma maneira, também buscamos verificar a sofisticação estatística das pesquisas. Do total de artigos empíricos, 187 (59,2\% dos artigos empíricos) fizeram uso de algum tipo de estatística contra 129 (40,8\% dos artigos empíricos) que não o fizeram. Não obstante, repetindo o padrão já visto em Sampaio, Bragatto e Nicolás (2016), a grande maioria dos trabalhos (135) lidou apenas com frequência simples (totalizando $72,2 \%$ dos artigos empíricos). A estatística univariada foi utilizada em 18 artigos (9,6\%), enquanto a estatística bivariada esteve presente em 34 estudos, o que representa 18,2\% dos estudos empíricos. O nosso resultado reforça o achado dos autores, que já denotavam uma curta gama de opções de técnicas de pesquisa e de uso de estatística na pesquisa sobre "Internet \& Política", algo também verdadeiro para a democracia digital. Não obstante, os números aqui presentes são significativamente melhores que aqueles vistos na pesquisa original, o que indica um progresso nesta seara.

Visando entender a relação e a centralização inesperada de casos entre a variáveis utilizadas neste estudo foram feitas tabelas de referência cruzada em conjunto com testes de qui-quadrado e de resíduo padrão, o qual tem por objetivo verificar a concentração de casos entre as categorias, a partir da análise entre os resultados esperados e obtidos, resultando nas tabelas a seguir.

Quando observada a relação entre a área de atuação do primeiro autor e o objeto político/social predominante abordado no artigo (Tabela 2) ${ }^{26}$, há uma presença maior do que a esperada de estudos sobre esfera civil não-organizada $(3,8)$ e movimentos sociais $(2,2)$ e uma presença menor do que a esperada de estudos sobre governo na Comunicação $(-2,3)$. Na Ciência Política, há notadamente mais estudos sobre campanhas eleitorais $(4,8)$ que o esperado. O Campo de Públicas, por sua vez, estuda mais governo $(2,0)$ e instituições de accountability $(2,7)$ que o esperado, enquanto a Administração só está acima do esperado para governo $(2,6)$, o mesmo valendo para a Ciência da Informação $(2,0)$. No Direito, políticas de comunicação/economia política é uma abordagem vista acima do esperado $(2,4)$.

26 Teste de qui-quadrado valor: 240,669; gl: 120; sig ,000 
Tabela 2. Cruzamento de área atuação do primeiro autor por objeto político predominante

\begin{tabular}{|c|c|c|c|c|c|c|c|c|c|c|}
\hline & \multirow{2}{*}{$\begin{array}{l}\text { Qual a área da atuação } \\
\text { do/a } 1 \text { autor/a? }\end{array}$} & \multicolumn{8}{|c|}{ Objeto político/social predominante analisado no artigo } & \multirow[b]{2}{*}{$\mathbf{N}$} \\
\hline & & $\begin{array}{l}\text { Políticas de } \\
\text { comunicação/ } \\
\text { Economia } \\
\text { Política }\end{array}$ & $\begin{array}{c}\text { esfera } \\
\text { civil não- } \\
\text { organizada }\end{array}$ & Governo & $\begin{array}{l}\text { Parlamentol } \\
\text { legislativo }\end{array}$ & $\begin{array}{l}\text { Campanhas } \\
\text { eleitorais }\end{array}$ & $\begin{array}{l}\text { Movimento } \\
\text { sociais }\end{array}$ & $\begin{array}{l}\text { Instituições de } \\
\text { accountability }\end{array}$ & Sociabilidade & \\
\hline $\mathrm{N}$ & \multirow{2}{*}{ Comunicação } & 28 & 51 & 17 & 9 & 7 & 14 & 2 & 5 & 133 \\
\hline $\begin{array}{l}\text { Resíduos } \\
\text { padronizados }\end{array}$ & & $-1,1$ & 3,8 & $-2,3$ & $-0,2$ & $-0,5$ & 2,2 & $-1,5$ &,- 1 & \\
\hline $\mathrm{N}$ & \multirow[b]{2}{*}{ Ciência Política } & 7 & 12 & 6 & 7 & 12 & 4 & 1 & 1 & 50 \\
\hline $\begin{array}{c}\text { Resíduos } \\
\text { padronizados }\end{array}$ & & $-1,7$ & 0,1 & $-1,6$ & 1,7 & 4,8 &, 5 &,- 8 &,- 7 & \\
\hline $\mathrm{N}$ & \multirow[b]{2}{*}{ Sociologia } & 8 & 4 & 4 & 1 & 1 & 0 & 0 & 1 & 19 \\
\hline $\begin{array}{c}\text { Resíduos } \\
\text { padronizados }\end{array}$ & & 1,4 & $-0,1$ &,- 1 &,- 3 &,- 2 & $-1,0$ & $-0,9$ & ,3 & \\
\hline $\mathrm{N}$ & \multirow[b]{2}{*}{ Ciências Sociais } & 5 & 1 & 2 & 1 & 3 & 2 & 2 & 1 & 17 \\
\hline $\begin{array}{c}\text { Resíduos } \\
\text { padronizados }\end{array}$ & & 0,1 & $-1,6$ & $-1,1$ & $-0,3$ & 1,7 & 0,9 & 1,4 & ,3 & \\
\hline $\mathrm{N}$ & \multirow{2}{*}{ Campo de Públicas } & 9 & 3 & 11 & 2 & 0 & 0 & 4 & 0 & 29 \\
\hline $\begin{array}{c}\text { Resíduos } \\
\text { padronizados }\end{array}$ & & 0,7 & $-1,3$ & 2,0 & 0 & $-1,3$ & $-1,3$ & 2,7 & $-1,0$ & \\
\hline $\mathrm{N}$ & \multirow{2}{*}{ Ciência da Informação } & 3 & 2 & 9 & 1 & 0 & 0 & 0 & 3 & 18 \\
\hline $\begin{array}{c}\text { Resíduos } \\
\text { padronizados }\end{array}$ & & $-1,1$ & $-1,3$ & 2,0 &,- 4 & $-1,2$ & $-1,1$ &,- 9 & 2,3 & \\
\hline
\end{tabular}




\begin{tabular}{|c|c|c|c|c|c|c|c|c|c|c|}
\hline & \multirow{2}{*}{$\begin{array}{l}\text { Qual a área da atuação } \\
\text { do/a } 1 \text { autor/a? }\end{array}$} & \multicolumn{8}{|c|}{ Objeto político/social predominante analisado no artigo } & \multirow[b]{2}{*}{$\mathbf{N}$} \\
\hline & & $\begin{array}{c}\text { Políticas de } \\
\text { comunicação/ } \\
\text { Economia } \\
\text { Política } \\
\end{array}$ & $\begin{array}{c}\text { esfera } \\
\text { civil não- } \\
\text { organizada }\end{array}$ & Governo & $\begin{array}{l}\text { Parlamento/ } \\
\text { legislativo }\end{array}$ & $\begin{array}{l}\text { Campanhas } \\
\text { eleitorais }\end{array}$ & $\begin{array}{l}\text { Movimento } \\
\text { sociais }\end{array}$ & $\begin{array}{l}\text { Instituições de } \\
\text { accountability }\end{array}$ & Sociabilidade & \\
\hline $\mathrm{N}$ & \multirow[b]{2}{*}{ Administração } & 11 & 4 & 15 & 4 & 0 & 1 & 0 & 1 & 36 \\
\hline $\begin{array}{c}\text { Resíduos } \\
\text { padronizados }\end{array}$ & & ,7 & $-1,4$ & 2,6 & ,9 & $-1,5$ & $-0,7$ & $-1,2$ &,- 3 & \\
\hline $\mathrm{N}$ & \multirow[b]{2}{*}{ Direito } & 28,0 & 15,0 & 12,0 & 3,0 & 2,0 & 1,0 & 5,0 & 3,0 & 69 \\
\hline $\begin{array}{c}\text { Resíduos } \\
\text { padronizados }\end{array}$ & & 2,4 & $-0,2$ & $-0,9$ &,- 9 & $-1,1$ & $-1,5$ & 1,2 & ,2 & \\
\hline $\mathrm{N}$ & \multirow{2}{*}{ Ciência da Computação } & 3,0 & 2,0 & 8,0 & 0 & 0,0 & 1,0 & 1,0 & , 0 & 15 \\
\hline $\begin{array}{c}\text { Resíduos } \\
\text { padronizados }\end{array}$ & &,- 3 & $-0,6$ & 2,9 & $-1,0$ & $-0,9$ & 0,2 & 0,6 &,- 7 & \\
\hline $\mathrm{N}$ & \multirow{2}{*}{$\begin{array}{c}\text { Relações } \\
\text { Internacionais }\end{array}$} & 0 & 0,0 & 0,0 & 0 & 1,0 & 1,0 & 0,0 & 0 & 2 \\
\hline $\begin{array}{c}\text { Resíduos } \\
\text { padronizados }\end{array}$ & &,- 7 & $-0,6$ & $-0,6$ &,- 4 & 2,7 & 2,8 & $-0,3$ &,- 3 & \\
\hline $\mathrm{N}$ & & 8,0 & 3,0 & 11,0 & 3,0 & 1,0 & 1,0 & 3,0 & 2,0 & 32 \\
\hline \multirow[t]{2}{*}{$\begin{array}{c}\text { Resíduos } \\
\text { padronizados }\end{array}$} & Outros &,- 5 & $-1,8$ & 1,0 & , 2 & $-0,9$ & $-0,8$ & 1,2 & ,4 & \\
\hline & Total & 110 & 97 & 95 & 31 & 27 & 25 & 18 & 17 & 420 \\
\hline
\end{tabular}

Fonte: Elaboração dos autores 
A concentração dos métodos utilizados nos artigos em comparação com a área de atuação (Tabela 3$)^{27}$ demonstra uma ocorrência maior que o esperado de trabalhos quantitativos dentro da Ciência Política $(3,2)$, enquanto, no Direito, ela ocorre pela maior presença de pesquisas bibliográficas $(4,3)$. Ainda no Direito, os trabalhos Quanti/Quali aparecem menos que o esperado $(-2,8)$. Novamente, esses resultados parecem ocorrer dentro do esperado, porém os dados podem ser um indicativo de pouca especialização metodológica da pesquisa sobre democracia digital.

Tabela 3. Cruzamento de área atuação do primeiro autor por método utilizado no artigo

\begin{tabular}{|c|c|c|c|c|c|c|}
\hline & \multirow{2}{*}{$\begin{array}{c}\text { Qual a área da } \\
\text { atuação do/a } 1 \\
\text { autor/a? }\end{array}$} & \multicolumn{5}{|c|}{ Tipo de método utilizado no artigo } \\
\hline & & Quantitativo & Qualitativo & Bibliográfico & Quanti/Quali & $\mathbf{N}$ \\
\hline $\mathrm{N}$ & Comunicação & 24 & 50 & 63 & 19 & 156 \\
\hline $\begin{array}{c}\text { Resíduos } \\
\text { padronizados }\end{array}$ & & $-1,2$ & , 3 & 0 & 1,1 & \\
\hline $\mathrm{N}$ & Ciência Política & 23 & 12 & 17 & 9 & 61 \\
\hline $\begin{array}{c}\text { Resíduos } \\
\text { padronizados }\end{array}$ & & 3,2 & $-1,5$ & $-1,5$ & 1,4 & \\
\hline $\mathrm{N}$ & Sociologia & 7 & 5 & 7 & 3 & 22 \\
\hline $\begin{array}{c}\text { Resíduos } \\
\text { padronizados }\end{array}$ & & 1,3 &,- 7 &,- 6 &, 7 & \\
\hline $\mathrm{N}$ & Ciências Sociais & 5 & 9 & 6 & 2 & 22 \\
\hline $\begin{array}{c}\text { Resíduos } \\
\text { padronizados }\end{array}$ & & ,3 & 0,9 & $-1,0$ & 0 & \\
\hline $\mathrm{N}$ & Campo de & 7 & 13 & 9 & 3 & 32 \\
\hline $\begin{array}{c}\text { Resíduos } \\
\text { padronizados }\end{array}$ & & 0,3 & 1,0 & $-1,1$ & 0,0 & \\
\hline $\mathrm{N}$ & Ciência da & 4 & 8 & 8 & 5 & 25 \\
\hline $\begin{array}{c}\text { Resíduos } \\
\text { padronizados }\end{array}$ & & $-0,4$ & 1 &,- 7 & 1,7 & \\
\hline $\mathrm{N}$ & Administração & 11 & 18 & 10 & 2 & 41 \\
\hline $\begin{array}{c}\text { Resíduos } \\
\text { padronizados }\end{array}$ & & 1,0 & 1,5 & $-1,6$ &,- 9 & \\
\hline $\mathrm{N}$ & Direito & 5 & 19 & 57 & 0 & 81 \\
\hline $\begin{array}{c}\text { Resíduos } \\
\text { padronizados }\end{array}$ & & $-2,8$ & $-1,2$ & 4,3 & $-2,8$ & \\
\hline
\end{tabular}

27 Teste de qui-quadrado valor: 83,263; gl: 30; sig ,000 


\begin{tabular}{|c|c|c|c|c|c|c|}
\hline & \multirow{2}{*}{$\begin{array}{c}\text { Qual a área da } \\
\text { atuação do/a } 1 \\
\text { autor/a? }\end{array}$} & \multicolumn{4}{|c|}{ Tipo de método utilizado no artigo } & \multirow[b]{2}{*}{$\mathbf{N}$} \\
\hline & & Quantitativo & Qualitativo & Bibliográfico & Quanti/Quali & \\
\hline $\mathrm{N}$ & \multirow{2}{*}{$\begin{array}{l}\text { Ciência da } \\
\text { Computação }\end{array}$} & 1 & 8 & 7 & 0 & 16 \\
\hline $\begin{array}{c}\text { Resíduos } \\
\text { padronizados }\end{array}$ & & $-1,2$ & 1,4 & 0,2 & $-1,2$ & \\
\hline $\mathrm{N}$ & \multirow{2}{*}{$\begin{array}{c}\text { Relações } \\
\text { Internacionais }\end{array}$} & 0 & 0 & 1 & 1 & 2 \\
\hline $\begin{array}{c}\text { Resíduos } \\
\text { padronizados }\end{array}$ & & $-0,6$ & $-0,8$ & 0,2 & 1,9 & \\
\hline $\mathrm{N}$ & Outros & 12 & 11 & 17 & 3 & 43 \\
\hline \multirow[t]{2}{*}{$\begin{array}{c}\text { Resíduos } \\
\text { padronizados }\end{array}$} & & 1,2 & $-0,6$ & $-0,1$ & $-0,5$ & \\
\hline & Total & 99 & 153 & 202 & 47 & 501 \\
\hline
\end{tabular}

Fonte: Elaboração dos autores

Finalmente, para tentarmos compreender como as pesquisas se comportam para além das suas áreas de origem, resolvemos cruzar as temáticas com os objetos tecnológicos, pois certas concentrações tenderiam a ser indicativos de especializações da área que independem das áreas de formação dos autores.

Conforme a tabela $4^{28}$, as pesquisas sobre transparência e informação já aparentam demonstrar tal especialização, já que evidenciam uma presença muito maior que a esperada em estudos sobre dados abertos $(7,2)$ e maior que a esperada sobre websites $(2,6)$, enquanto apresentam menor presença que o esperado avaliando a internet como um todo $(-3,3)$ e mídias sociais $(-2,8)$. A participação foi mais vista que o esperado em estudos de websites $(3,4)$, enquanto deliberação já mostrou bastante especialização com foco em fóruns e chats $(5,5)$ e mídias sociais $(4,2)$, enquanto avaliou menos que o esperado a internet como um todo e dados abertos (-2,2, cada). Da mesma maneira, engajamento e mobilização estiveram fortemente centrados em mídias sociais $(5,6)$ e ocorreu menos que o esperado em websites $(-2,9)$ e dados abertos $(-2,1)$. Dentro do esperado, estudos baseados na teoria da democracia digital tenderam a tomar a internet como um todo como seu objeto de estudo $(2,1)$, mas surpreendentemente lidaram menos que o esperado com mídias sociais $(-2,2)$, evidenciando falta de um olhar mais atento sobre esses objetos tecnológicos mais recentes. A internet como um todo também predominou mais

28 Teste de qui-quadrado valor: 347,232; gl: 110; sig ,000. 
que o esperado em abordagens de inclusão/exclusão digital $(3,4)$ e políticas de comunicação/economia política $(2,1)$.

Esses dados em conjunto parecem indicar razoável especialização das subáreas em avaliar determinados objetos quando não temos as áreas dos autores em vista. Esse pode ser visto como um indicativo do supracitado campo da democracia digital, que iremos debater com mais exaustão durante a conclusão.

\section{Conclusão}

Esse artigo apresenta os resultados de uma pesquisa que buscou mapear e analisar a produção acadêmica em periódicos científicos sobre democracia digital. A busca no Google Scholar foi considerada a mais adequada para se captar os periódicos presentes nas mais diversas bases de indexação, portanto o objetivo era alcançar toda a população de artigos. Para enriquecer os dados e aumentar a chance de nos aproximarmos da população total de artigos, complementamos os dados do GS com artigos obtidos no DOAJ, buscados através da plataforma Dimensions. Não obstante, um limite da pesquisa é evidentemente dado pelo próprio GS, que não apresenta uma API ou uma forma inteiramente válida para se baixar os metadados das referências (a exemplo do que é possível em SciELO, Scopus e Web of Science), que foram gerados manualmente para este artigo. Ainda com tais estratégias, compreende-se que alguns artigos possam não estar presentes em nosso corpus, por serem mal indexados e difíceis de serem encontrados, mesmo usando ferramentas mais abrangentes. Outro limite da pesquisa é o fato de lidar com dados amplos e exploratórios e não apresentar testes de hipóteses e/ou estatísticos mais rigorosos. Apesar de estarmos lidando com o universo de artigos, parece-nos que passos mais sofisticados e rigorosos metodologicamente podem ser dados, o que se pretende fazer em futuras pesquisas. ${ }^{29}$

A partir da presente análise de periódicos, revela-se notável que a literatura de democracia digital apresente, de forma geral, características muito próximas da literatura de "Internet \& Política" e do campo da Comunicação e Política. A pesquisa interdisciplinar, portanto, gera poucas alterações nos resultados, o que evidencia que a democracia digital é naturalmente um objeto

29 Notadamente, desejamos fazer mais cruzamentos entre os dados, buscando compreender especificidades dos diferentes campos atuando na área, através de análises de redes e análises de correspondências múltiplas dos dados categóricos e análises léxicas de resumos e palavras-chave. 
dessas áreas. Uma surpresa foi a entrada do Direito como área de alta presença no corpus, algo que praticamente não havia sido detectado em nenhum estudo anterior (ver: FREITAS et al., 2020).

A literatura de democracia digital apresenta oscilações normais ao longo dos anos, mas traz uma trajetória ascendente clara, evidenciando um maior interesse a cada ano em suas temáticas. Notadamente, nos últimos cinco anos, novas áreas estão claramente se apropriando da temática de maneira mais enfática, fortalecendo essa elevação.

Sobre as universidades, o lugar de destaque de UFPR, UFBA, UFMG e UnB reforça achados de pesquisas anteriores sobre "Internet \& Política", enquanto a entrada da USP parece se justificar pela entrada de pesquisas de outras áreas. Por sua vez, nossa pesquisa detectou a entrada de Unesp e UFSM na temática.

Ao contrário da literatura sobre "Internet \& Política", foi identificada uma presença maior da vertente institucional sobre a social. É notável como o item Políticas de Comunicação/Economia Política da Comunicação assume o primeiro lugar como principal temática da democracia digital. Trata-se de um tema já estudado anteriormente por pesquisadores de Comunicação e, em menor medida, Ciência Política, mas que é reforçado por pesquisadores do Campo de Públicas (especialmente interessados na governança digital) e, notadamente, no Direito, que ganha força na área nos últimos anos. Entre as pesquisas de vertente social, é igualmente notável o interesse na chamada esfera civil não-organizada, representada, especialmente, pelos grandes movimentos organizados e/ou ocorridos em ambientes digitais, a exemplo das manifestações de junho de 2013, manifestações e movimentos a favor e contra o impeachment da presidenta Dilma Rousseff em 2015 e 2016 e, evidentemente, durante as diversas eleições presidenciais e locais a partir de 2014.

À semelhança de "Internet \& Política", pesquisadores de democracia digital analisaram mais a internet como um todo, em menor escala verificando websites e mídias sociais - mais raramente ainda estudando plataformas sociais específicas, como o Facebook. Não obstante, é importante notar que essa especialização aumenta ao longo do tempo. Conforme visto na literatura de "Internet \& Política" no Brasil e na internacional de democracia digital (GOMES, 2016), as principais abordagens teóricas são de e-transparência, e-participação, e-deliberação e teoria da democracia digital. Diferentemente de estudos anteriores, em 
nossa pesquisa, a transparência digital assume a ponta das pesquisas, algo que deve se justificar pela entrada das novas áreas pesquisadas e também por uma queda geral de objetos de participação (digital ou presencial) no país nos últimos anos. E, como na literatura de "Internet \& Política", a maioria dos artigos baseia-se em estudos empíricos, basicamente assentados em análise de conteúdo.

Mas, afinal, recapitulando a nossa pergunta de pesquisa, existe um campo da democracia digital no Brasil? Possivelmente, no sentido mais estrito do conceito de campo acadêmico (BOURDIEU, 1988), a resposta seja não. Afinal, diferentemente da pesquisa anglo-saxã, não temos um conjunto considerável de associações, congressos ou mesmo periódicos especializados na temática e não se trata de uma subárea reconhecida por CAPES ou CNPq (não existe, por exemplo, a subárea "democracia digital" no currículo Lattes). Além disso, não são conhecidas linhas de pesquisa específicas nos programas de pós-graduação.

Por outro lado, nossos resultados são indicativos de que há sim uma lógica de um campo, se formos flexíveis o suficiente. Basicamente, o campo da democracia digital brasileira é formado pelas áreas de Comunicação Social e Ciência Política, portando fortes relações com o subcampo da Comunicação e Política. Enquanto essa conclusão pode soar relativamente evidente a princípio, devemos nos lembrar que o mesmo não ocorre na literatura internacional, conforme os argumentos de Gomes (2016), que a avalia como uma área de confluência ou convivência. No caso brasileiro, a Administração e o Campo de Públicas, de um lado, e o Direito, do outro, seriam as áreas de convivência, inclusive por terem uma produção mais recente.

Pelo argumento do campo, as principais referências fazem forte coro. A grande maioria está ou na área de Comunicação ou na "área" de Política (Ciência Política ou Filosofia Política) e a análise dessa rede de citações também se organizou em torno de autores desses domínios, notadamente autores brasileiros que reconhecidamente lidam com a literatura de democracia digital. O mesmo valendo para os periódicos. Por um lado, vemos uma flagrante fragmentação, afinal 502 artigos foram publicados em 261 periódicos. Por outro, a iminência de periódicos de Comunicação, Administração Pública e Ciência Política novamente confirma como a democracia digital é majoritariamente produzida por pesquisadores dessas áreas. Para além das áreas, tanto os estudos anteriores revisados quanto os nossos resultados apontam que 
já existem centros acadêmicos (universidades) de referência na produção sobre o tema igualmente e, portanto, já existem autores e instituições-líderes reconhecidas pela área de democracia digital, por assim dizer.

Se quisermos argumentar contra a ideia de um campo, mesmo num sentido menos estrito, para além da supracitada fragmentação das publicações, podemos reforçar que a maioria dos artigos não apresenta nem uma parceria interinstitucional $(75,3 \%)$ e nem interdisciplinar $(74,4 \%)$, evidenciando uma baixa colaboração entre pesquisadores de diferentes áreas e universidades. Em outras palavras, os pesquisadores aqui avaliadores parecem frequentemente publicar nas revistas de suas áreas de origem e com outros pesquisadores do mesmo domínio.

Argumentamos que cerca de um quarto de interdisciplinaridade não é um valor desprezível e que nossos dados longitudinalmente evidenciam um crescimento das colaborações acadêmicas entre as áreas dos autores. Ademais, nossa hipótese é que esse resultado está mais conectado à forma de organização e avaliação da pós-graduação brasileira que ao campo em si. Em outras palavras, não há um incentivo para um pesquisador de Comunicação, por exemplo, publicar em uma revista de Ciência Política (e vice-versa), uma vez que os Qualis das revistas tendem a ser muito distintos entre as áreas. ${ }^{30}$ No sentido racional e estratégico, o mais lógico é o pesquisador permanecer em seu campo de origem, em termos de publicação, e, no máximo, acionar os autores de referência do campo de forma mais independente, o que nos parece ser exatamente o que ocorre no caso em tela.

Nossos dados indicam que temos ao menos áreas, instituições, autores e periódicos de referência para o que seria um campo interdisciplinar da democracia digital, basicamente composto pela Comunicação e Ciência Política. ${ }^{31}$ Nossos dados reforçam os achados de Pinho et al. (2019) e de Vianna Júnior, Abreu e Batista (2020) de que a Administração teria uma entrada na democracia digital, porém mais tardia e mais tímida. Não obstante, é notável o crescimento da produção do Campo de Públicas, possivelmente por seu interesse em temáticas da governança digital. Neste momento, se juntássemos Administração e o Campo de Públicas, eles já estariam em terceiro lugar, à frente da Ciência

30 Leite e Codato (2013) já denotaram a importância do Qualis para a autonomização da ciência política por exemplo. Com o vindouro Qualis único, mudanças mais significativas podem ser esperadas nesse comportamento.

31 Fizemos a classificação das áreas conforme a descrição dos artigos, como determina a análise de conteúdo, mas certos artigos do campo de públicas e de ciências sociais foram escritos por cientistas políticos, o que reforça essa nossa afirmação. 
Política. Como já pontuado, a entrada do Direito tende a modificar os dados agregados em um futuro próximo, entretanto, até o momento, não há indicativos de significativas trocas acadêmicas entre essas áreas e os atores mais antigos do campo. Dito de outra forma, teríamos um campo da democracia digital brasileiro basicamente organizado em torno de Comunicação e Ciência Política, no qual há razoáveis trocas acadêmicas (para um campo interdisciplinar), porém que também recebe contribuições das áreas de Administração, do Campo de Públicas e da área de Direito, essas ainda mais autocentradas. O Direito, em especial, tende apenas a crescer em importância em termos de produção, porém ainda precisa aumentar seu diálogo com as outras áreas.

Se, naquele momento, a pesquisa de Sampaio, Bragatto e Nicolás (2016) parecia indicar um viés do recorte de pesquisa escolhido pelos autores, isto é, o estudo de papers de eventos de comunicação e de ciências sociais, agora já temos um indicativo de que seus resultados parecem se comprovar. Na literatura brasileira, uma considerável parte (se não a maior) da literatura sobre "Internet \& Política" é organizada notadamente sobre democracia digital e nessas áreas de pesquisa.

Isso nos soa, substancialmente, diferente do apontado por Wilson Gomes (2016) na literatura internacional, na qual a democracia digital pode até ser a área de origem dos estudos, mas que agora só representa um subcampo consideravelmente menor que a política online. A literatura internacional já apresenta um nível de especialização que parece conformar cada tópico como praticamente um subcampo à parte. Logo, teríamos o subcampo da e-participação, da deliberação online, da transparência digital e daí por diante. Possivelmente, a literatura brasileira esteja caminhando para tal especialização, mas certamente não se trata do cenário atual.

Como reflexão inicial, especialmente em um momento que os estudos sobre democracia digital parecem estar em questionamento de sua própria importância, a pesquisa sobre democracia digital poderia ter ganhos se houvesse um esforço para uma ainda maior consolidação de um campo de pesquisa no sentido mais estrito. Enquanto é normal e esperado que cada área de origem possa ter uma contribuição mais específica no campo, parece-nos que mais trocas acadêmicas poderiam levar a consideráveis ganhos em termos teóricos e, especialmente, metodológicos. 
A rede formada pelo Instituto Nacional de Ciência e Tecnologia em Democracia Digital (INCT.DD) ${ }^{32}$ parece indicar um bom caminho, uma vez que incentiva trocas acadêmicas entre seus membros de diferentes áreas, promovendo eventos, cursos e treinamentos. Todavia, a rede formada ainda não alcança totalmente alguns nichos no interior de outras áreas para além da Comunicação e Política. Portanto, a formação de outras redes, parcerias, eventos especializados (e mesmo a criação de grupos de trabalho em eventos já consolidados) continua, no atual momento, sendo bem-vinda.

\section{Referências}

ALDÉ, A.; SANTOS, J.; SANTOS, V. Redes de pesquisa sobre Internet \& Política no Brasil: uma análise de redes multidimensional da pesquisa de pós-graduação na área entre 2000 e 2017. In: Encontro Anual da ANPOCS, 42., 2018, Caxambu. Anais eletrônicos... disponível em: http://www.anpocs. com/index.php/encontros/papers/42-encontro-anual-da-anpocs/gt-31/ gt02-26/11117-redes-de-pesquisa-sobre-internet-e-politica-no-brasil-uma-analise-de-redes-multidimensional-da-pesquisa-de-pos-graduacao-na-area-entre-2000-e-2017?format=html\&path=42-encontro-anual-da-anpocs/gt-31/gt02-26. Acesso em: 17 mar. 2020.

ALMADA, M. et al. Democracia digital no Brasil. Matrizes, São Paulo, v. 13, p. 161-181, 2019.

BLONDEL, V. et al. Fast unfolding of communities in large networks. Journal of statistical mechanics: theory and experiment, Bristol, n. 10, p. P10008, 2008.

BOURDIEU, P. Homo academicus. Stanford: Stanford University Press, 1988. COLEMAN, S.; BLUMLER, J. The internet and democratic citizenship: theory, practice and policy. Cambridge: Cambridge University Press, 2009. COMPOLÍTICA. diretório de teses e dissertações em comunicação e política: banco de dados. 2019. Disponível em: http://compolitica.org/novo/teses. Acesso em: 16 nov. 2021.

CURTINOVI, J.; PARMEGGIANI, B. Investigações sobre democracia digital no Brasil: um mapeamento da produção acadêmica até 2013. Revista Comunicando, Lisboa, n. 4, p. 99-116, 2015.

32 Mais informações em: https://inctdd.org/. 
DIMENSIONS. data and solutions for discovery and analytics: base indexadora de referências acadêmicas. 2021. Disponível em: https://app.dimensions.ai/. Acesso 30 ago. 2021.

CÂMARA DOS DEPUTADOS. e-DEMOCRACIA. 2009. Disponível em: https://edemocracia.camara.leg.br/ Acesso em: 16 de nov. de 2021.

FREITAS, C. et al. Análise da rede de produção de conhecimento sobre a iniciativa e-democracia. Revista e-Legis, Brasília, v. 13, p. 182-203, 2020.

GOMES, W. 20 Anos de Política, Estado e Democracia Digitais: uma cartografia do campo. In: SILVA, S.; BRAGATTO, R.; SAMPAIO, R. (orgs.). Democracia digital, comunicação política e redes: teoria e prática. Rio de Janeiro: Letra \& Imagem, 2016. p. 39-76.

GRÁCIO, M. Análises relacionais de citação para a identificação de domínios científicos. São Paulo: Cultura Acadêmica, 2020.

LEITE, F.; CODATO, A. Autonomização e institucionalização da Ciência Política brasileira: o papel do sistema Qualis-Capes. Agenda Política, São Carlos, v. 1, n. 1, 2013.

MUGNAINI, R. et al. Panorama da produção científica do Brasil além da indexação: uma análise exploratória da comunicação em periódicos. Transinformação, Campinas, n. 31, p. 1-15, 2019.

NEUENDORF, K. The content analysis guidebook. Thousand Oaks: Sage, 2002. PINHO, J. et al. Democracia Digital na área de administração: um levantamento da construção do campo no Brasil. Cadernos de Gestão Pública, São Paulo, v. 24, n. 78, p. 1-31, 2019.

PRZEYBILOVICZ, E.; CUNHA, M.; COELHO, T. O desenvolvimento dos estudos sobre governo eletrônico no Brasil. Um estudo bibliométrico e sociométrico. RESI (Revista Eletrônica de Sistemas de Informação), Curitiba, v. 14, n. 3, p. 1-24, 2015.

ROTHBERG, D. Por uma agenda de pesquisa em democracia eletrônica. Opinião Pública, Campinas, v. 14, n. 1, p. 149-172, 2008.

SAMPAIO, R.; BRAGATTO, R.; NICOLÁS, M. A construção do campo de internet e política: análise dos artigos brasileiros apresentados entre 2000 e 2014. Revista Brasileira de Ciência Política, Brasília, v. 4, n. 21, p. 285 320, 2016.

SAMPAIO, R. et al. Livro de Códigos - Estado da Arte da Democracia Digital no 
Brasil. 2021. Disponível em: https://bdc.c3sl.ufpr.br/handle/123456789/98. Acesso em: 25 out. 2021.

SANTOS, J.; ALDÉ, A.; SCHWAMBACH, A. Panorama das teses e dissertações brasileiras envolvendo Internet e Política de 1995 a 2014. In: Encontro Anual da ANPOCS, 40, 2016, Caxambu. Anais eletrônicos... Disponível em: https://www.anpocs.com/index.php/papers-40-encontro Acesso em: 17 mar. 2020.

SILVA, S.; BRAGATTO, R.; SAMPAIO, R. Concepções, debates e desafios da democracia digital. In: SILVA, S.; BRAGATTO, R.; SAMPAIO, R. (orgs.). Democracia digital, comunicação política e redes. Rio de Janeiro: Letra \& Imagem, 2016. p. 17-38.

VEDEL, T. The idea of electronic democracy: Origins, visions and questions. Parliamentary Affairs, Oxford, v. 59, n. 2, p. 226-235, 2006.

VIANNA JUNIOR, A.; ABREU, J.; BATISTA, W. Democracia digital e participação cidadã: uma análise bibliométrica. Organizações \& Sociedade, Salvador, v. 19, n. 2, p. 49-62, 2018.

\section{O campo da Democracia Digital brasileira: uma análise cientomé- trica de artigos publicados entre 1999 e 2020}

Resumo: Este artigo investiga a produção acadêmica em periódicos sobre a democracia digital no Brasil. Foi realizada uma busca automatizada no Google Scholar e DOAJ por palavras-chave e, após a filtragem manual, o corpus empírico resultou em 502 artigos. Estes artigos foram avaliados com base em análise de conteúdo, buscando identificar as principais características dos autores, assim como as abordagens teóricas e empíricas. Depois, as referências foram avaliadas através da análise de redes. Os resultados evidenciam a hegemonia dos campos da comunicação e da ciência política, um predomínio de análises sobre a esfera civil não organizada e o uso dos conceitos de participação e deliberação. A maioria dos artigos é empírica, faz uso da técnica de análise de conteúdo e privilegia a avaliação de websites e mídias sociais. Concluímos argumentando pela existência de um campo da democracia digital.

Palavras-chave: democracia digital, governo eletrônico, participação política online, transparência digital, cientometria. 


\section{The Brazilian e-democracy field: a scientometric analysis of articles published between 1999 and 2020}

Abstract: This article investigates academic production on e-democracy in Brazilian journals. An automated search was performed on Google Scholar and DOAJ for keywords and, after manual filtering, resulted in an empirical corpus of 502 articles. Content analysis of these articles identified the main characteristics of the authors and the theoretical and empirical approaches to the subject. Network analysis analyzed relationships among references. The results show that these studies are largely conducted within the fields of communication and political science, that they tend to focus on the non-organized civil sphere, and that they often mobilize the concepts of participation and deliberation. Most of the articles are empirical using content analysis to examine websites and social media. We conclude by defending the construction of e-democracy as an academic field in Brazil.

Keywords: e-democracy, e-government, e-participation, e-transparency, Scientometrics.

Submetido em 02 de abril de 2021

Aprovado em 14 de outubro de 2021 